\title{
The Organization of Cerebellar and Basal Ganglia Outputs to Primary Motor Cortex as Revealed by Retrograde Transneuronal Transport of Herpes Simplex Virus Type 1
}

\author{
John E. Hoover ${ }^{1}$ and Peter L. Strick ${ }^{2,3}$ \\ ${ }^{1}$ Department of Biology, Millersville University, Millersville, Pennsylvania 17551, ${ }^{2}$ Research Service (151S), Veterans Affairs \\ Medical Center, Syracuse, New York 13210, and '3epartments of Neurosurgery and Neuroscience and Physiology, State \\ University of New York Health Science Center, Syracuse, New York 13210
}

\begin{abstract}
We used retrograde transneuronal transport of herpes simplex virus type 1 to map the origin of cerebellar and basal ganglia "projections" to leg, arm, and face areas of the primary motor cortex (M1). Four to five days after virus injections into M1, we observed many densely labeled neurons in localized regions of the output nuclei of the cerebellum and basal ganglia. The largest numbers of these neurons were found in portions of the dentate nucleus and the internal segment of the globus pallidus (GPi). Smaller numbers of labeled neurons were found in portions of the interpositus nucleus and the substantia nigra pars reticulata. The distribution of neuronal labeling varied with the cortical injection site. For example, within the dentate, neurons labeled from leg M1 were located rostrally, those from face M1 caudally, and those from arm M1 at intermediate levels. In each
\end{abstract}

instance, labeled neurons were confined to approximately the dorsal third of the nucleus. Within GPi, neurons labeled from leg M1 were located in dorsal and medial regions, those from face M1 in ventral and lateral regions, and those from arm M1 in intermediate regions. These results demonstrate that $M 1$ is the target of somatotopically organized outputs from both the cerebellum and basal ganglia. Surprisingly, the projections to M1 originate from only $30 \%$ of the volume of the dentate and $<15 \%$ of GPi. Thus, the majority of the outputs from the cerebellum and basal ganglia are directed to cortical areas other than $\mathrm{M} 1$.

Key words: primary motor cortex; cerebellum; basal ganglia; thalamus; transneuronal transport; herpes simplex virus; primate; motor control
The cerebellum and basal ganglia are critically involved in voluntary motor control, contributing to the programming, initiation, and execution of limb and eye movements (Brooks and Thach, 1981; DeLong and Georgopoulos, 1981). Dysfunction of these subcortical nuclei can result in profound motor disturbances (e.g., ataxia, dysmetria, tremor, rigidity, and bradykinesia). The outputs of the cerebellum and basal ganglia are mediated, in part, through projections to various thalamic nuclei (for review, see Percheron et al., 1996). However, the cortical target or targets of the thalamic nuclei that receive cerebellar or basal ganglia efferents have been the subject of considerable controversy. For example, some have argued that the cerebellothalamocortical system is focused entirely on a single cortical area, the primary motor cortex (M1; Kemp and Powell, 1971; Asanuma et al., 1983). On the other hand, the density and even the existence of a basal ganglia-thalamocortical pathway to M1 has been questioned (for references and discussion, see Holsapple et al., 1991). Thus, one of the main goals of our study was to examine a fundamental issue about cerebellar and basal ganglia outputs; the presence and organization of projections to M1.

\footnotetext{
Received April 30, 1998; revised Nov. 24, 1998; accepted Dec. 2, 1998.

This work was supported by the Veterans Affairs Medical Research Service and by United States Public Health Service Grant Research Service (151S), Veterans Affairs Medical Center, Syracuse, NY 13210. We thank M. Page for the development of computer programs and M. Evans, S. Fitzpatrick, K. Hughes and M. O'Malley-Davis for their expert technical assistance. We also thank Drs. D. I. Bernstein (Gamble Institute of Medical Research, Cincinnati, OH) and R. D. Dix (Bascom Palmer Eye Institute, Miami, FL) for supplying HSV1.

Correspondence should be addressed to Dr. Peter L. Strick, Research Service, (151S), Veterans Affairs Medical Center, Syracuse, NY 13210.

Copyright (ㄷ) 1999 Society for Neuroscience $0270-6474 / 99 / 191446-18 \$ 05.00 / 0$
}

Attempts to map cerebellar and basal ganglia projections to the cerebral cortex with conventional tracers have been hindered by a number of technical limitations. Chief among these is the multisynaptic nature of these pathways and the general inability of conventional tracers to label more than the direct inputs and outputs of an area. To overcome this and other problems, we have used a new approach, retrograde transneuronal transport of herpes simplex virus type 1 (HSV1, McIntyre-B strain). This tracing method can effectively label a chain of up to three synaptically linked neurons in a single experiment (for review, see Strick and Card, 1992). In the present study, we have used retrograde transneuronal transport of HSV1 to label the origin of cerebellothalamocortical and pallidothalamocortical projections to the face, arm, and leg areas of M1.

There are four major results from this study. First, a survival period of 4-5 d is optimal for the transneuronal transport of HSV1 from "first order" neurons in the ventrolateral thalamus that innervate the injection site to "second order" neurons in the output nuclei of the cerebellum and basal ganglia. Second, the face, arm, and leg representations of M1 are each targets of outputs from both the cerebellum and basal ganglia. Third, the regions of the dentate nucleus and internal segment of the globus pallidus (GPi) that project to M1 via the thalamus contain spatially separate face, arm, and leg areas. This result suggests that both of these subcortical nuclei contain at least one map of the body. Fourth, projections to M1 originate from only $30 \%$ of the volume of the dentate and $<15 \%$ of GPi. Thus, although the cerebellum and basal ganglia both project to M1, the majority of their outputs are directed to other cortical areas. 


\begin{tabular}{|c|c|c|c|c|c|c|c|}
\hline Animal & $\begin{array}{l}\text { Region of } \\
\text { M1 injected }\end{array}$ & $\begin{array}{l}\text { Virus titer } \\
(\mathrm{pfu} / \mathrm{ml})\end{array}$ & $\begin{array}{l}\text { \# of surface } \\
\text { penetrations }\end{array}$ & $\begin{array}{l}\# \text { of sulcal } \\
\text { penetrations }\end{array}$ & $\begin{array}{l}\text { Total \# of } \\
\text { injections }\end{array}$ & $\begin{array}{l}\text { Total volume } \\
\text { injected }(\mu \mathrm{l})\end{array}$ & $\begin{array}{l}\text { Survival } \\
\text { period (d) }\end{array}$ \\
\hline $\mathrm{Z} 10$ & Arm & $6.1 \times 10^{8}$ & 2 & 2 & 8 & 0.40 & 4.5 \\
\hline Jo 19 & Arm & $8.2 \times 10^{8}$ & 7 & 4 & 19 & 0.95 & 4.7 \\
\hline Jo $20^{a}$ & Arm & $3.6 \times 10^{10}$ & 4 & 4 & 16 & 0.80 & 4.8 \\
\hline Jo 17 & Leg & $8.2 \times 10^{8}$ & 9 & 0 & 9 & 0.45 & 4.8 \\
\hline Jo 18 & Face & $8.2 \times 10^{8}$ & 9 & 0 & 9 & 0.45 & 4.6 \\
\hline Jo 25 & Arm & $8.2 \times 10^{8}$ & 4 & 4 & 16 & 0.80 & 2.0 \\
\hline Jo 26 & Arm & $8.2 \times 10^{8}$ & 4 & 4 & 16 & 0.80 & 3.0 \\
\hline Jo 21 & Arm & $8.2 \times 10^{8}$ & 8 & 4 & 20 & 1.0 & 7.0 \\
\hline
\end{tabular}

${ }^{a}$ This animal was injected with a modified strain of McIntyre-B HSV-1. See Materials and Methods.

Some of these results have been reported in preliminary form (Hoover and Strick, 1992, 1993a,b).

\section{MATERIALS AND METHODS}

This report is based on observations from 10 juvenile cebus monkeys (Cebus apella, 1.4-2.0 kg). Eight of these animals received multiple injections of HSV1 (McIntyre-B) into either the $\operatorname{arm}(n=6)$, leg $(n=1)$, or face $(n=1)$ representation of M1. Two animals received multiple injections of wheat germ agglutinin conjugated to horseradish peroxidase (WGA-HRP) into the arm representation of M1. Cortical injection sites were identified using sulcal landmarks and intracortical stimulation (see below).

Surgical procedures, electrophysiological mapping, and virus injections. Approximately $12 \mathrm{hr}$ before surgery, each animal was administered dexamethasone (Decadron; $0.5 \mathrm{mg} / \mathrm{kg}$, i.m.) and restricted from food and water. The animal was anesthetized for surgery using a mixture of tiletamine and zolazepam (Telazol; initial dose, $20 \mathrm{mg} / \mathrm{kg}$, i.m.; supplemental dose, $5-7 \mathrm{mg} \cdot \mathrm{kg}^{-1} \cdot \mathrm{hr}^{-1}$, i.m. $)$. Atropine sulfate $(0.05 \mathrm{mg} / \mathrm{kg}$, i.m.), dexamethasone (0.5 mg/kg, i.m.), and an antibiotic (Kefzol; 25 $\mathrm{mg} / \mathrm{kg}$, i.m.) were also given at this time. Respiratory rate and depth, heart rate, blood oxygen saturation, and body temperature were continually monitored during the surgery. Hydration was maintained using lactated Ringer's solution (10 cc/hr, i.v.); temperature was regulated with a heating pad. In some instances, an analgesic, butorphanol (Torbugesic; $0.1-.4 \mathrm{mg} / \mathrm{kg}$, i.m.), was given every $2-4 \mathrm{hr}$ during surgery to reduce the amount of anesthetic necessary for the procedure and to relieve any potential discomfort associated with the surgery.

All surgical procedures were conducted using aseptic techniques. Each animal's head was placed in a stereotaxic frame. A bolt was then attached to the skull with small screws and dental acrylic to stabilize the head during physiological mapping. A large craniotomy was performed over the left frontal lobe. The dura was then incised and reflected medially to expose the central sulcus, the genu of the arcuate sulcus, and the superior precentral dimple. The cortex was covered with warm surgical grade silicone (Dow Corning, $1500 \mathrm{cSt}$ ).

In most animals, the face, arm, or leg representation of M1 was physiologically mapped using intracortical stimulation (12-20 cathodal pulses, $0.2 \mathrm{msec}$ duration, $300 \mathrm{~Hz}$ frequency, 1-25 $\mu \mathrm{A}$ intensity) with glass-coated Elgiloy microelectrodes (Suzuki and Azuma, 1976; impedance $=0.6-1.4 \mathrm{M} \Omega$ at $1 \mathrm{kHz}$ ). The stimulus intensity was monitored by an isolated "passive current probe" that measures the current passing through the wire to the microelectrode. The site of each microelectrode penetration was observed through a dissecting microscope and marked on an enlarged view of the brain that had been image-captured using a video camera/computer system. Microelectrode penetrations, spaced $0.5-1.0 \mathrm{~mm}$ apart, were made into the precentral gyrus and the anterior bank of the central sulcus. For penetrations into the gyrus, stimulation was delivered $1.5-1.7 \mathrm{~mm}$ below the cortical surface. For penetrations into the sulcus, stimulation was delivered every $100-250 \mu \mathrm{m}$, beginning $1.5 \mathrm{~mm}$ below the cortical surface and extending an additional $3.0 \mathrm{~mm}$. The number of penetrations made in each experiment was intentionally limited to reduce the length of time the animal was under anesthesia and to minimize damage to the cortex.

The motor response evoked at each stimulation site was determined by visual inspection and muscle palpation. The threshold current for each response was defined as the stimulus intensity that evoked movement in $50 \%$ of the trials. These data were entered into a computer program that generated two- and three-dimensional maps of the cortical areas stimulated. These maps were subsequently used to guide tracer injections into an identified body representation.

After the mapping was completed, the silicone was washed from the surface of the cortex using warm $\left(38^{\circ} \mathrm{C}\right)$ physiological saline. Then, a tracer was injected at multiple sites within the face, arm, or leg representation of M1. In seven animals, we injected the McIntyre-B strain of HSV1 (supplied by Dr. David Bernstein, Gamble Institute of Medical Research, Cincinnati, OH) (McClean et al., 1989). In one animal, we injected a strain of McIntyre-B that had been cultured in African green monkey kidney cells (supplied by Dr. Richard Dix, University of Miami School of Medicine, Miami, FL) (Dix et al., 1983). The specific parameters associated with each virus experiment, such as the region of cortex injected, the virus titer, the number of injection sites, the total volume of virus injected, and the survival period, are summarized in Table 1. In two additional animals, we injected WGA-HRP (Sigma, St. Louis, MO; 10\% in $0.5 \mathrm{M} \mathrm{NaCl}$ with $0.1 \mathrm{M}$ mannose) into the arm representation of M1.

Injections into the anterior bank of the central sulcus were placed at depths of $1.5,2.5$, and $3.5 \mathrm{~mm}$ below the cortical surface. Injections into the precentral gyrus were placed at a depth of $1.5 \mathrm{~mm}$. Injections were made with a $5 \mu \mathrm{l}$ Hamilton syringe; the volume of tracer injected at each location was $50 \mathrm{nl}$. After each injection, the microsyringe was left in place for 1-2 min. When the injections were completed, the dura and bone flap were repositioned, and the wound was closed in layers.

The procedures adopted for this study and the care provided experimental animals conformed to the regulations detailed in the National Institutes of Health Guide for the Care and Use of Laboratory Animals. All protocols were reviewed and approved by the institutional Animal Care and Use Committees. The biosafety precautions taken during these experiments conformed to or exceeded the BSL-2 regulations detailed in Health and Human Services Public (Biosafety in Microbiological and Biomedical Laboratories). A detailed description of the procedures for
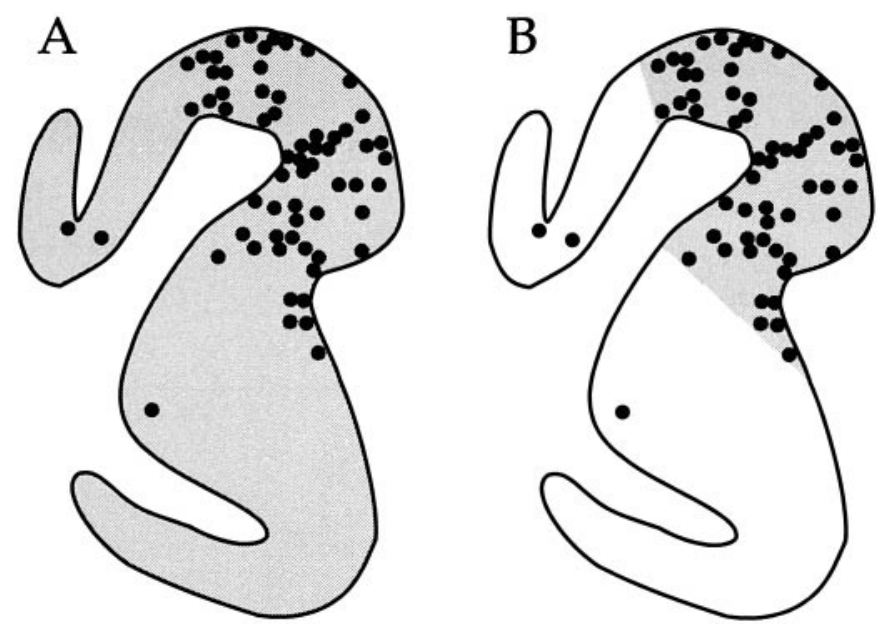

Figure 1. Examples of regions outlined to make area measurements (shaded areas). Two regions were outlined: $A$, the entire nucleus; and $B$, the region containing most $(>90 \%)$ of the labeled neurons. 

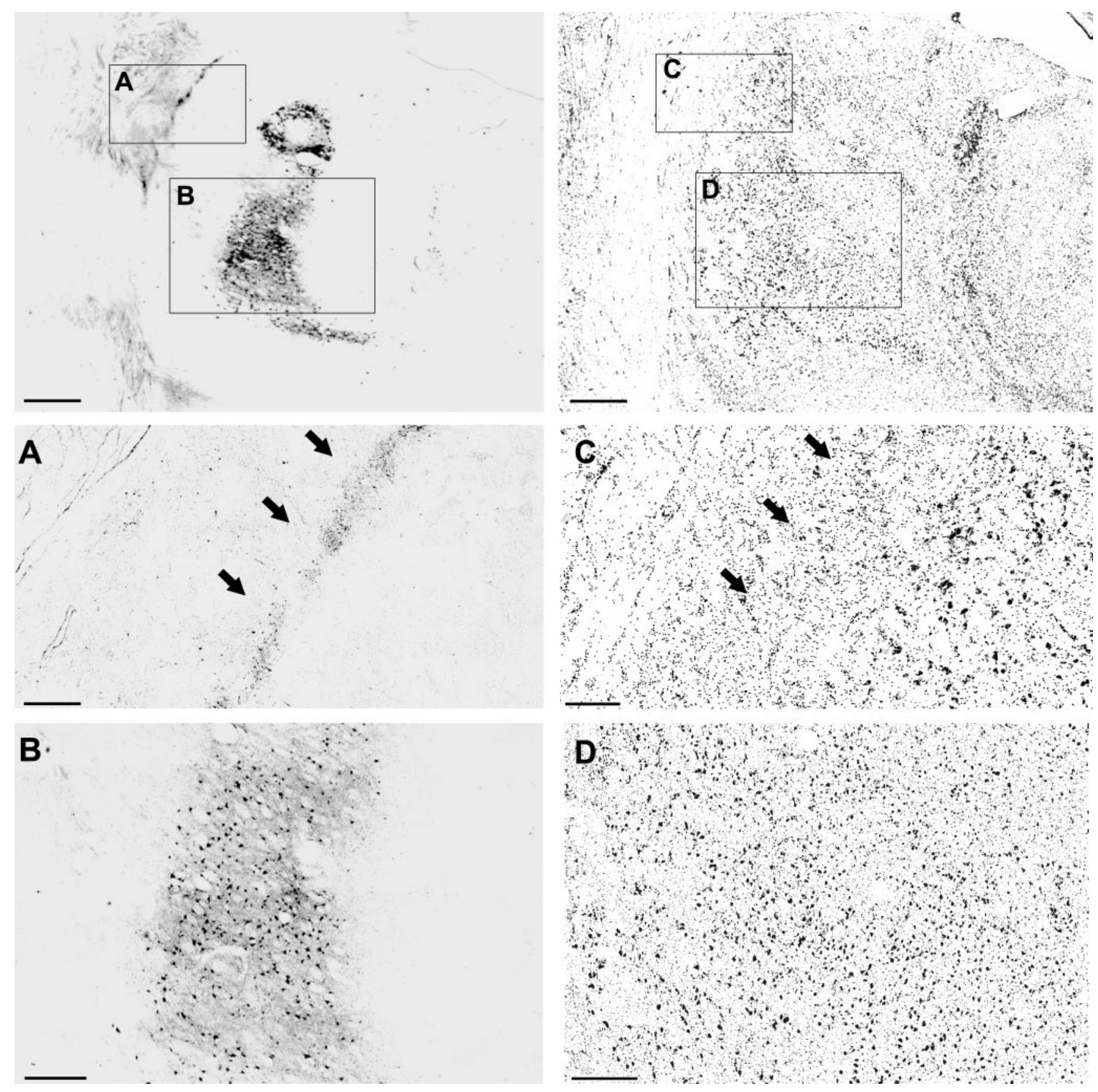

Figure 2. Ventrolateral thalamus of animal Jo 22. Top left, Neuronal cell bodies in VPLo labeled by retrograde transport of WGA-HRP from arm M1 (box $B)$. Also, axonal terminal fields in the reticular nucleus labeled by anterograde transport of WGA-HRP (box A). Top right, An adjacent section stained with cresyl violet. The boxed areas in the top row are shown at higher magnification in the middle and bottom rows. Middle, Reticular nucleus $(A$, $C)$. Bottom, VPLo $(B, D)$. Arrows in $A$ and $C$ point to the reticular nucleus. Scale bars: top row, $1 \mathrm{~mm} ;$ middle, bottom row, $100 \mu \mathrm{m}$.

handling virus and virus-infected animals is presented in Strick and Card (1992).

Histological procedures. After a survival period of 2-7 d (Table 1), each animal was deeply anesthetized (ketamine hydrochloride, $25 \mathrm{mg} / \mathrm{kg}$, i.m.; pentobarbital sodium, $40 \mathrm{mg} / \mathrm{kg}$, i.p.) and transcardially perfused using a three-step procedure (Rosene and Mesulam, 1978). The perfusates included: $0.1 \mathrm{M}$ phosphate buffer, $4 \%(\mathrm{w} / \mathrm{v})$ paraformaldehyde in phosphate buffer, and $4 \%$ paraformaldehyde in phosphate buffer with $10 \%$ (v/v) glycerol. After the perfusion, the brain and spinal cord were removed and stored in buffered $4 \%$ paraformaldehyde with $20 \%$ glycerol $\left(4^{\circ} \mathrm{C}\right)$ for $5-10 \mathrm{~d}$.

Blocks of neural tissue were frozen (Rosene et al., 1986) and serially sectioned $(50 \mu \mathrm{m})$ in the coronal plane. To identify neurons labeled by virus transport, we processed free-floating tissue sections according to the avidin-biotin peroxidase method (Vectastain; Vector Laboratories, Burlingame, CA) using a commercially available antibody to HSV1 [Dako, Carpinteria, CA; 1:2000 dilution; see Strick and Card (1992) for additional details]. We used the tetramethylbenzidine method (Mesulam, 1982; Gibson et al., 1984) to identify neurons labeled by WGA-HRP. At least every third section from each animal was appropriately processed to demonstrate labeled neurons. Every tenth section was post-fixed and counterstained with cresyl violet for cytoarchitectonic analysis (E. C. Gower, in Mesulam, 1982).

Analytical procedures. Tissue sections were examined under bright-field and dark-field polarized illumination. Section outlines and labeled neurons were plotted using a computerized charting system (MD2; Minnesota Datametrics, St. Paul, MN). This system uses optical encoders to 
sense $x-y$ movements of the microscope stage and stores the coordinates of charted structures.

We used Cavalieri's estimator of morphometric volume (Rosen and Harry, 1990) to determine the proportion of the dentate nucleus and GPi that "projects" to M1. Cavalieri's rule provides a statistically unbiased method for the approximation of brain volume from area measurements of serial sections:

$$
\mathrm{V}_{\mathrm{c}}=d\left(\sum_{i=1}^{n}\left(y_{\mathrm{i}}\right)\right)-(t) y_{\max }
$$

where, $d=$ distance between the sections that are being analyzed, $y_{\mathrm{i}}=$ cross-sectional area of the $i^{\text {th }}$ section through the region of interest, $n=$ total number of sections, $y_{\max }=$ the maximum value of $y$, and $t=\operatorname{section}$ thickness. To obtain the required area measurements, we used a computer program that analyzed regions of the MD2 files outlined with a cursor. For each section through the dentate nucleus and GPi, two measurements were made: (1) the total cross-sectional area of the nucleus; and (2) the area of the nucleus containing most $(>90 \%)$ of the labeled neurons (Fig. 1).

\section{RESULTS}

Our results are presented in two major sections. In the first section, we describe the spatiotemporal patterns of viral labeling seen after HSV1 (McIntyre-B) injections into M1. We compare these patterns with those seen after similarly placed injections of WGA-HRP. In the second section, we present topographic analyses of cerebellar and basal ganglia labeling seen after retrograde transneuronal transport of HSV1 from the face, arm, and leg representations of M1.

\section{Spatial and temporal patterns of transport}

To determine the appropriate survival period for mapping of cerebellothalamocortical and basal ganglia-thalamocortical pathways, we examined the patterns of viral labeling seen after three different survival times: $2-3 \mathrm{~d}, 4-5 \mathrm{~d}$, and $7 \mathrm{~d}$. For comparison, we examined the patterns of labeling seen $2 \mathrm{~d}$ after cortical injections of WGA-HRP. In each of these experiments, the tracer was injected into the arm area of M1 (see below for details).

\section{Two to three days after injection of WGA-HRP or HSV1}

In primates, M1 is known to receive inputs from a number of cortical and subcortical sites, including multiple motor areas of the frontal lobe (ipsilateral and contralateral hemispheres), portions of parietal and posterior parietal cortex, and specific regions of the ventrolateral thalamus, thalamic midline, and intralaminar nuclei, and the nucleus basalis of Meynert (for review, see Dum and Strick, 1991). Retrograde transport of WGA-HRP from the arm area of M1 in the cebus monkey labeled neurons in all of these sites. We examined the thalamic labeling in some detail and found labeled neurons in portions of ventralis lateralis pars oralis (VLo), ventralis lateralis pars caudalis (VLc), and ventralis posterior lateralis pars oralis (VPLo) (Fig. 2). In fact, the distribution of thalamic labeling, as well as that in other subcortical and cortical sites, was comparable to what has been previously reported for the macaque (for review, see Dum and Strick, 1991; Holsapple et al., 1991).

Two to three days after injection of HSV1 (McIntyre-B) into the arm area of M1, all of the regions known to project to M1 contained neurons infected with virus. For example, within the thalamus, we observed virus-labeled neurons in portions of VLo, VPLo, and VLc (Fig. 3). Immunoreactive staining filled the somata, proximal dendrites, and in some cases, distal dendrites of labeled cells. In contrast, the neuropil surrounding labeled neu-
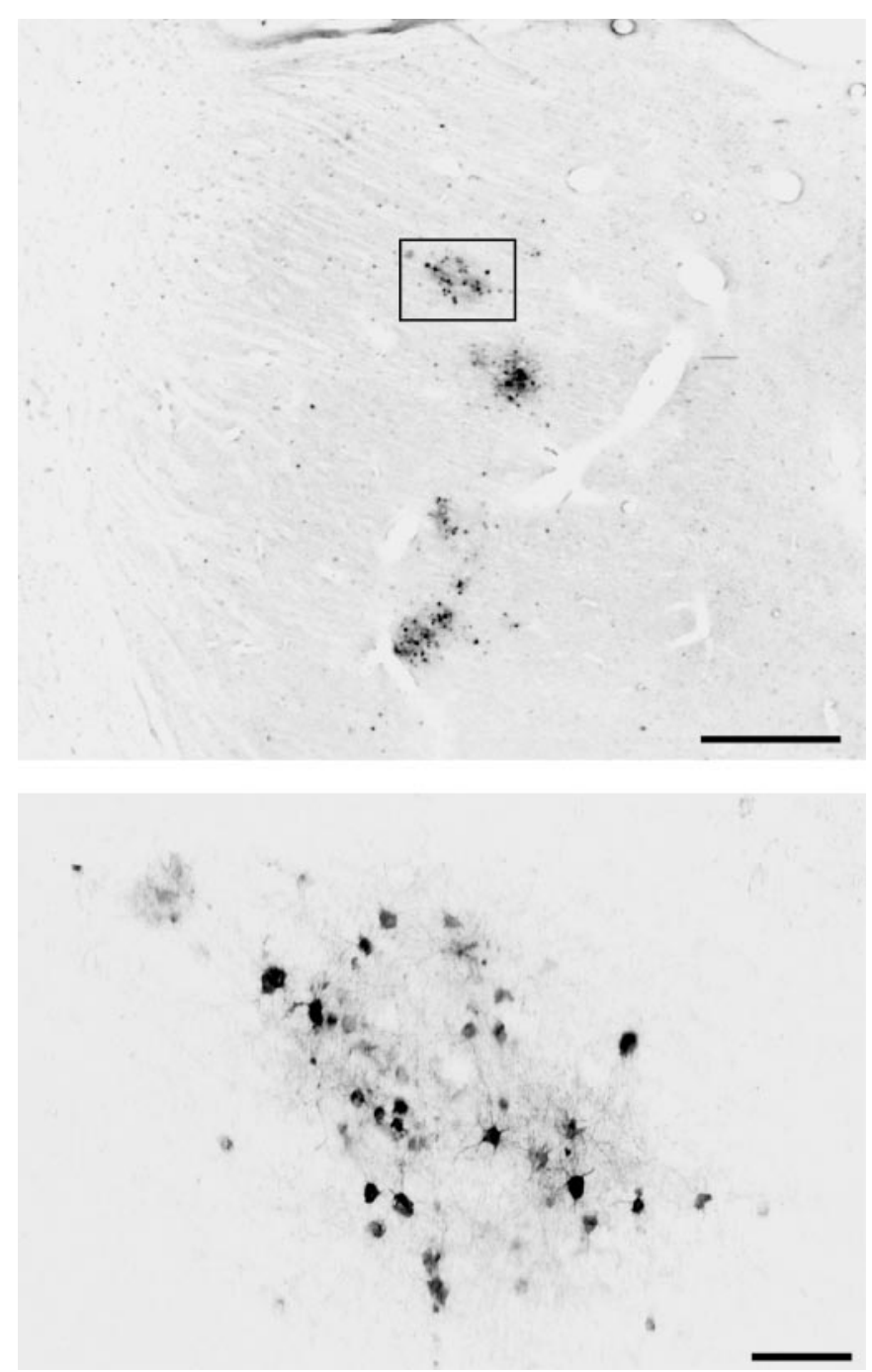

Figure 3. Ventrolateral thalamus of animal Jo 26. Top, First order neurons in VPLo labeled by retrograde transport of virus from arm M1; survival period of $3 \mathrm{~d}$. Scale bar, $1 \mathrm{~mm}$. Bottom, Higher magnification view of the boxed area at the top. Scale bar, $100 \mu \mathrm{m}$. Note that the virus-labeled cells have features typical of thalamocortical neurons.

rons showed only pale immunoreactive staining. There was little or no evidence of cellular destruction or pathology in and around infected neurons at this survival time. Taken together, these observations are consistent with retrograde transport of HSV1 (McIntyre-B) by cortical and subcortical neurons innervating M1.

In primates, the output of M1 is directed toward a number of cortical and subcortical sites. Some of these sites lack a direct reciprocal connection back on motor cortex. Among these are portions of the putamen, pontine nuclei, red nucleus, dorsal column nuclei, and spinal cord. As expected, injections of WGAHRP into arm M1 of the cebus monkey resulted in anterograde labeling in all of these sites. In contrast, no virus-infected neurons were observed at any of these sites after equivalent injections of HSV1 (McIntyre-B). Thus, we found no evidence for anterograde transport of HSV1 (McIntyre-B) by M1 efferents. These observations support the previous conclusion that the McIntyre-B strain of HSV1 is transported selectively in the retrograde direction (McClean et al., 1989; Zemanick et al., 1991; Hoover and Strick, 1993b; Middleton and Strick, 1994). 


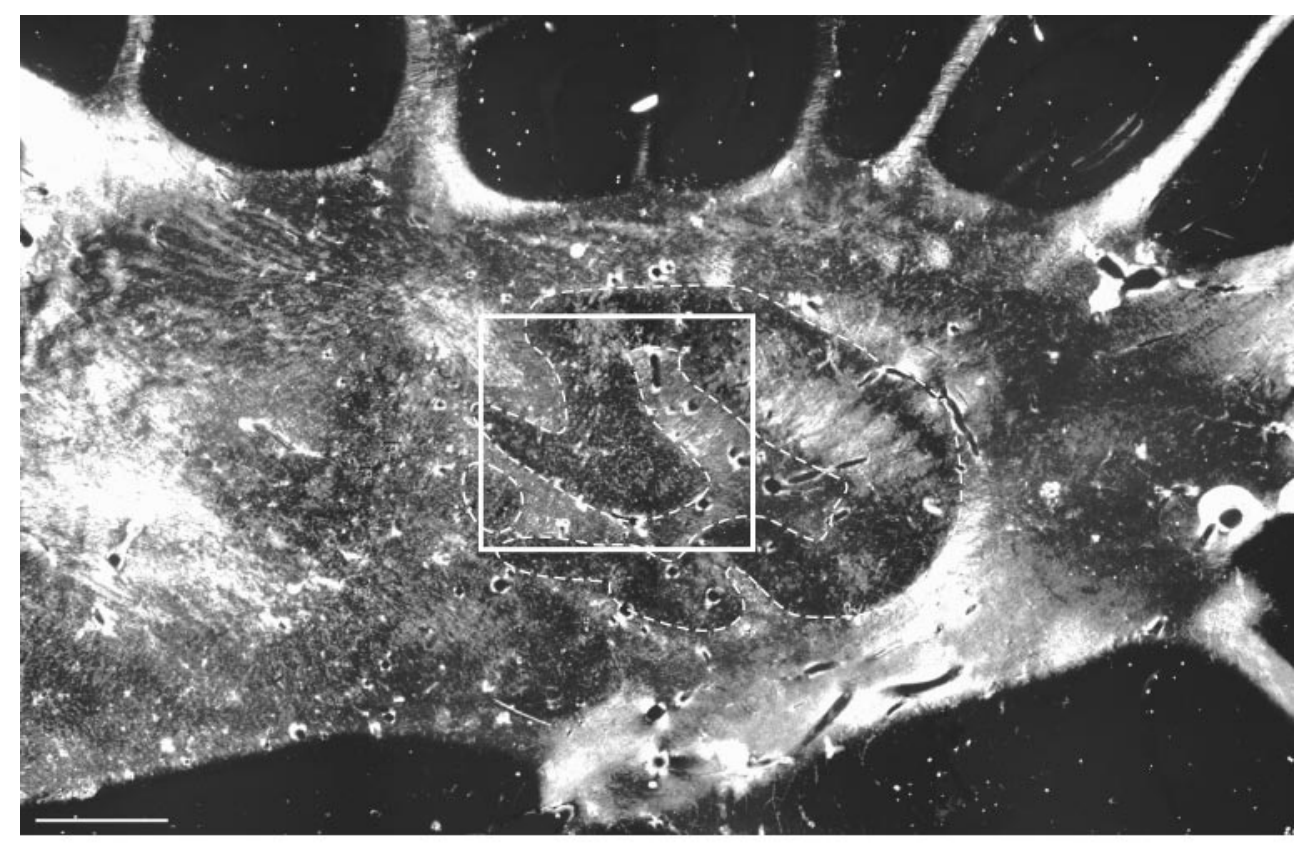

Figure 4. Cerebellar deep nuclei of animal Z10. Top, Dark-field view of the dentate and interpositus nuclei. Scale bar, $1 \mathrm{~mm}$. Bottom left, Higher magnification view of the boxed area at the top showing second-order neurons labeled by retrograde transneuronal transport of virus from arm M1; survival period of 4.5 d. Scale bar, $500 \mu \mathrm{m}$. Bottom right, Higher magnification view of the boxed area at the left. Scale bar, $50 \mu \mathrm{m}$.
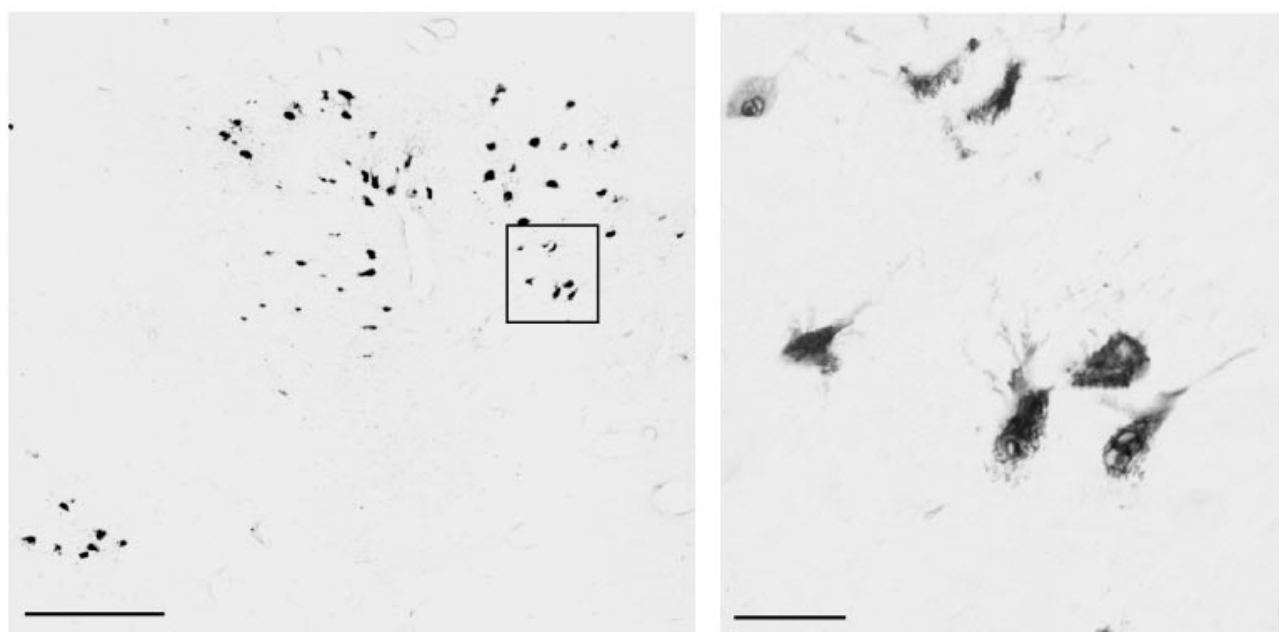

\section{Four to five days after injection of HSV1}

After a survival period of 4-5 d, cortical injections of HSV1 (McIntyre-B) resulted in a pattern of labeling that differed in two major respects from that described above. The most important difference was the presence of neurons infected with virus in specific portions of the cerebellar deep nuclei and the internal segment of the globus pallidus (Figs. 4, 5). Examination of sections stained with cresyl violet, in regions containing the greatest density of labeled neurons, revealed that an average of $40-50 \%$ of the neurons in the dentate nucleus and GPi were infected with virus. In individual cases, as many as $65-70 \%$ of the neurons were infected with virus. In the cerebellum (Fig. 4), the labeled neurons typically had large, round cell bodies with multiple dendrites. The dendritic arborizations were dense and compact, with many branchings near the somata. In the globus pallidus (Fig. 5), the labeled neurons had elliptical somata, with one or more radiating dendrites. The primary dendrites coursed obliquely through the nucleus but were most concentrated within the area of the labeled cell bodies. The cerebellar deep nuclei are known to project to VPLo, and GPi is known to project to VLo (for review, see Schell and Strick, 1984; Holsapple et al., 1991) (see also Rouiller et al., 1994; Kayahara and Nakano, 1996). There- fore, the pattern of cerebellar and pallidal labeling is consistent with uptake and retrograde transport of HSV1 (McIntyre-B) by first-order neurons in thalamus that innervate the injection site, and then retrograde transneuronal transport of virus from these first-order neurons to second-order neurons in the cerebellar deep nuclei and GPi (Fig. 6).

The second major difference between the pattern of labeling after a 4-5 d survival period and that after shorter times was the density and distribution of thalamic labeling. At the longer survival time, many more thalamic neurons were labeled with virus (Fig. 7). Some of these were swollen and contained vacuoles. Thalamic regions with large numbers of labeled neurons also displayed dense staining for viral antigen in the neuropil. Some of this staining could be traced to the processes of labeled neurons and adjacent glial cells. In addition, it is possible some was extracellular, resulting from the lysis of infected cells. It is important to note, however, that dense staining of the neuropil was present only when neurons were already labeled at subcortical sites. These observations suggest that the transneuronal transfer of virus occurred before the infection progressed to the point of cellular lysis and the potential extracellular release of virus.

The regions of the thalamus containing labeled neurons ipsi- 

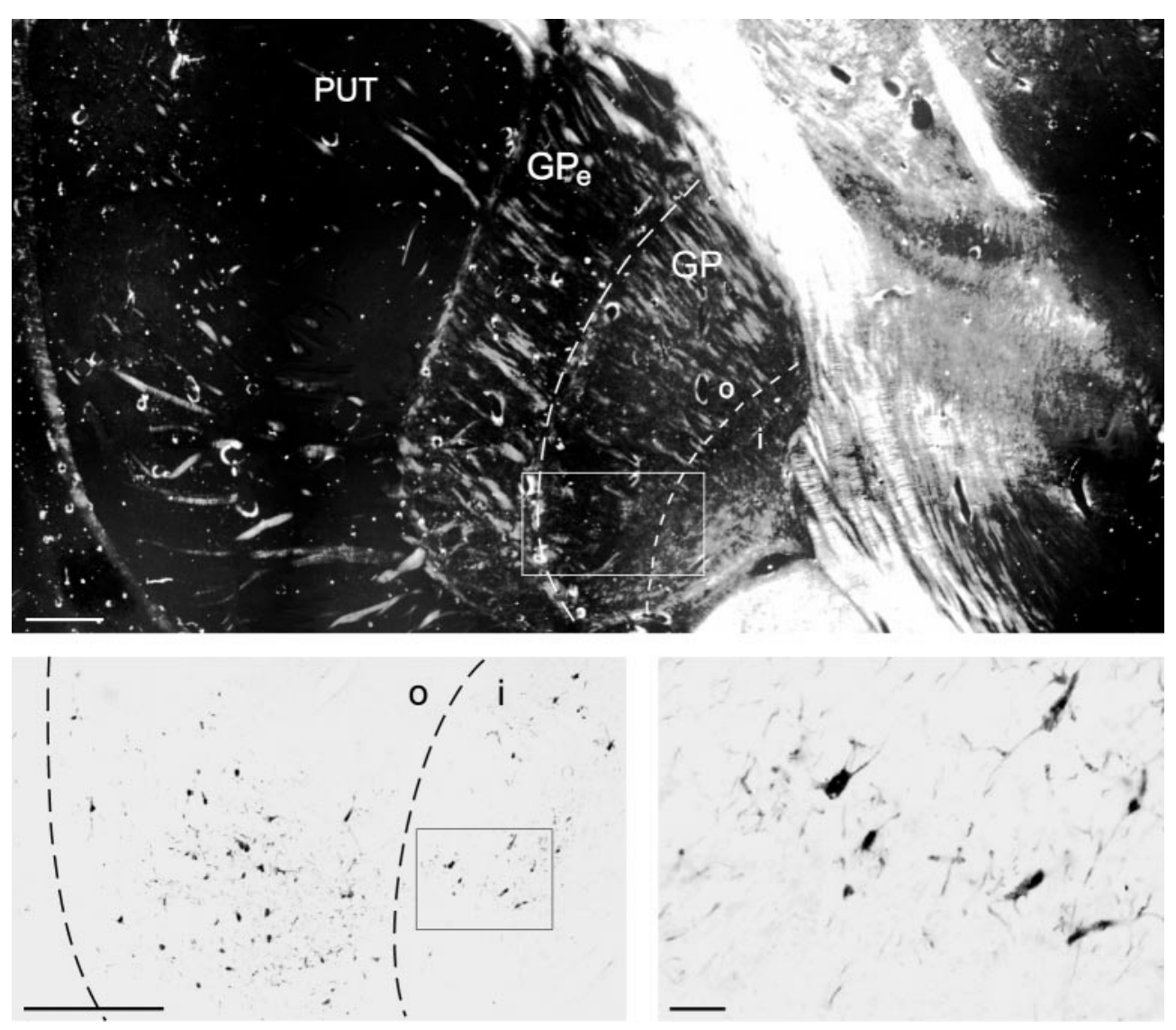

Figure 5. Basal ganglia of animal Z10. Top, Dark-field view of the globus pallidus and putamen. Scale bar, $1 \mathrm{~mm}$. Bottom left, Higher magnification view of the boxed area at the top showing secondorder neurons in GPi labeled by retrograde transneuronal transport of virus from arm M1; survival period of $4.5 \mathrm{~d}$. Scale bar, $500 \mu \mathrm{m}$. Bottom right, Higher magnification view of the boxed area at the left. Scale bar, $50 \mu \mathrm{m}$. GPe, External segment of GP; $i$, inner portion of GPi; $o$, outer portion of GPi; PUT, putamen.

\section{IPSILATERAL}

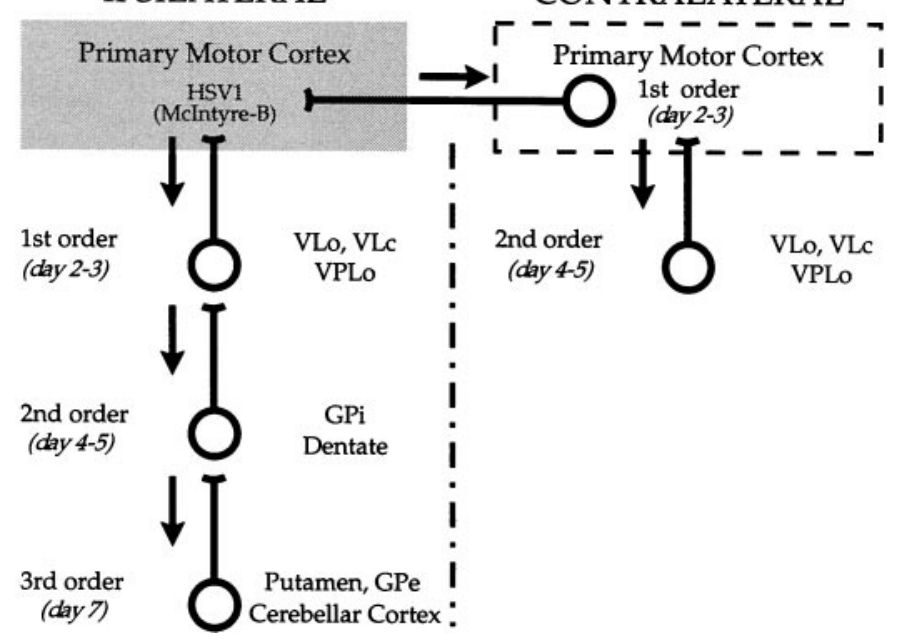

Figure 6. Schematic summary of the spatiotemporal patterns of labeling after virus injections into arm M1. Arrows indicate the direction of transport, retrograde, and retrograde transneuronal.

lateral to the cortical injection site were more extensive than those seen at shorter survival times. For example, virus-labeled neurons were observed in portions of area $\mathrm{X}$, as well as additional areas of VLo, VPLo, and VLc. We believe that this pattern of labeling can be explained by retrograde transport of HSV1 (McIntyre-B) by first-order neurons in cortical areas of the ipsilateral hemisphere that project to the injection site (e.g., supplementary motor area and ventral premotor area) and then retrograde transneuronal transport of virus by second-order neurons in the thalamus that innervate these cortical areas. Consistent with this view was the observation that most of the labeled neurons in these additional areas of thalamus appeared to be at an earlier stage of infection than those seen in thalamic areas that project directly to the injection site.

In addition to more extensive labeling in the ipsilateral thalamus, neurons infected with virus were also present in the thalamus contralateral to the injected hemisphere. These were observed in portions of VLo, VPLo, and VLc, mirroring the distribution seen in the ipsilateral thalamus after a 3 d survival time (see above). The density of labeled neurons in the contralateral thalamus was markedly less than that at matching sites in the ipsilateral thalamus, and the labeling was characteristic of an earlier stage of infection. We believe that this pattern of labeling can be explained by retrograde transport of virus by first-order cortical neurons in the contralateral M1 that project to the injection site through the corpus callosum and then retrograde transneuronal transport from these first-order neurons to second-order neurons in the contralateral thalamus (Fig. 6).

\section{Seven days after injection of HSV1}

We allowed animal Jo 21 to survive for $7 \mathrm{~d}$ after cortical injections of HSV1 (McIntyre-B). The most important finding from this experiment was the additional presence of virus-labeled neurons in the cerebellar cortex, an area unlabeled in all of our other experiments. Specifically, isolated Purkinje cells infected with HSV1 were found within paravermal and lateral zones of cerebellar cortex (Fig. 8). In addition, highly localized patches of the outer molecular layer showed massive glial proliferation. HSV1-labeled processes, including occasional glial cells, were found within these regions. In some instances, the patches of glial 

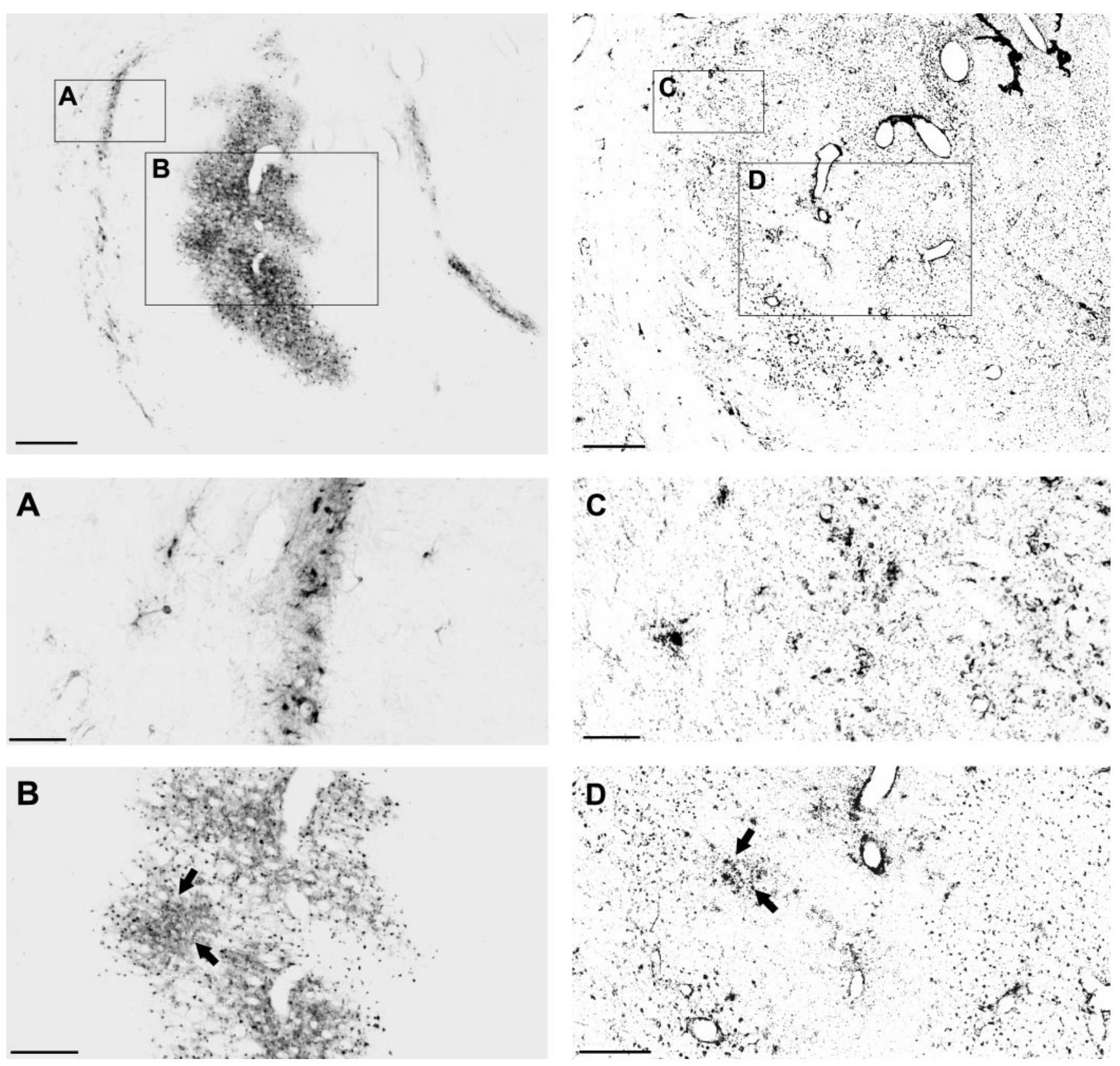

Figure 7. Ventrolateral thalamus of animal Jo 20. Top left, Thalamic neurons in VLo labeled by retrograde transport of virus from arm M1 (box B); survival period of $4.8 \mathrm{~d}$. Also, second-order neurons in the reticular nucleus labeled by retrograde transneuronal transport (box $A$ ). Top right, An adjacent section stained with cresyl violet. The boxed areas in the top row are shown at higher magnification in the middle and bottom rows. Middle, Reticular nucleus $(A, C)$. Bottom, VLo $(B, D)$. Arrows in $B$ and $D$ point to a localized site of intense gliosis and neuronal cell loss. Scale bars: top row, 1 mm; middle, bottom row, $100 \mu \mathrm{m}$.

proliferation surrounded the dendritic trees of labeled Purkinje cells. In other cases, as revealed in cresyl violet stained sections, Purkinje cells were noticeably absent immediately below the glial patches. The regions of cerebellar cortex containing labeled Purkinje cells and/or zones of glial proliferation are known to innervate the regions of the deep nuclei that contained labeled neurons (Eager, 1966; Tolbert et al., 1977, 1978; Tolbert and Bantli, 1979). Thus, the labeling in cerebellar cortex suggests an additional stage of retrograde transneuronal transport of HSV1 (McIntyre-B) from second-order neurons in the cerebellar deep nuclei to thirdorder Purkinje cells in the cerebellar cortex (Fig. 6).

Similarly, within the basal ganglia of animal Jo 21, a small number of labeled neurons was additionally present in the "sensorimotor portions" of the putamen and external segment of the globus pallidus (GPe). These areas were unlabeled in all of our other experiments. The portions of the putamen and GPe that contained labeled neurons in the $7 \mathrm{~d}$ animal are known to innervate the regions of GPi that contained labeled neurons in animals that survived 4-5 d (Hazrati et al., 1990; Hazrati and Parent, 1992; Flaherty and Graybiel, 1993, 1994). Thus, the pattern of labeling in the basal ganglia after a $7 \mathrm{~d}$ survival period is consistent with an additional stage of retrograde transneuronal transport of HSV1 (McIntyre-B) from second-order neurons in GPi to third-order neurons in the putamen and GPe (Fig. 6). 


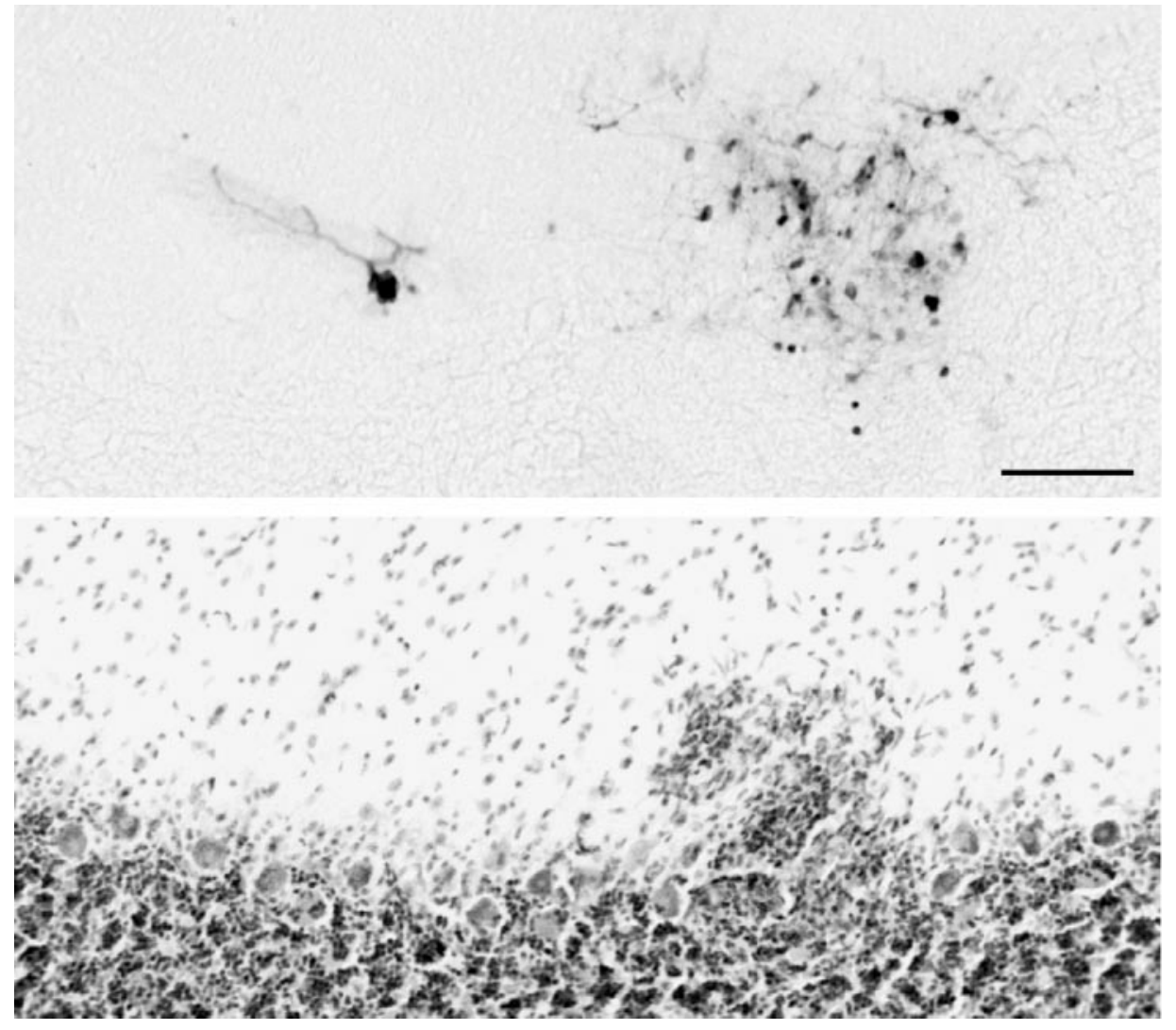

Figure 8. Cerebellar cortex of animal Jo 21. Top, Third-order neurons labeled in cerebellar cortex by retrograde transneuronal transport of virus from arm M1; survival period of $7.0 \mathrm{~d}$. The Purkinje cell layer runs horizontally through the approximate middle of the micrograph (see bottom). Note the virus-labeled neuron in the Purkinje cell layer (left) and cluster of labeled somata and processes in the outer molecular and inner granular layers (right). Bottom, An adjacent section stained with cresyl violet. Note the glial proliferation in the outer molecular layer (right). Scale bar, $100 \mu \mathrm{m}$.
Taken together, the results reported above provide evidence that careful adjustment of survival time can be used to reveal different links in a chain of synaptically connected neurons. The primary goal of the present study was to examine the organization of cerebellar and pallidal outputs to M1. This required adjusting the survival time to allow labeling of second- but not third-order neurons. Our results demonstrated that this could be accomplished by restricting the survival period to $4-5 \mathrm{~d}$. The remainder of this report describes the organization of cerebellothalamocortical and basal ganglia-thalamocortical connections to M1 using the pattern of viral labeling seen after survival periods of 4-5 d.

\section{Topographic analyses}

\section{Injection sites $(4-5 d)$}

We were able to distinguish two concentric zones of immunoreactive labeling at cortical injection sites, termed central and peripheral zones (Fig. 9). The central zone, located immediately adjacent to the needle track, was characterized by dense and largely uniform immunoreactive staining for virus and marked tissue necrosis. In some instances, this zone was lost during histological processing. The peripheral zone contained some neuronal lysis and a less dense accumulation of reaction product. In this zone, some darkly labeled neurons, in an advanced phase of infection, could be distinguished from the background staining of the neuropil. In each experiment, we defined an injection site (Figs. 10-13) as including both the central and peripheral zones. Although we have considered this to be the effective area of virus uptake for transneuronal transport, it is possible that the effective site is actually limited to the central zone. In general, the spread of virus from cortical injections was relatively limited. Five days after injecting a volume of $50 \mathrm{nl}$, the radial spread of the injection was typically $500-750 \mu \mathrm{m}$.
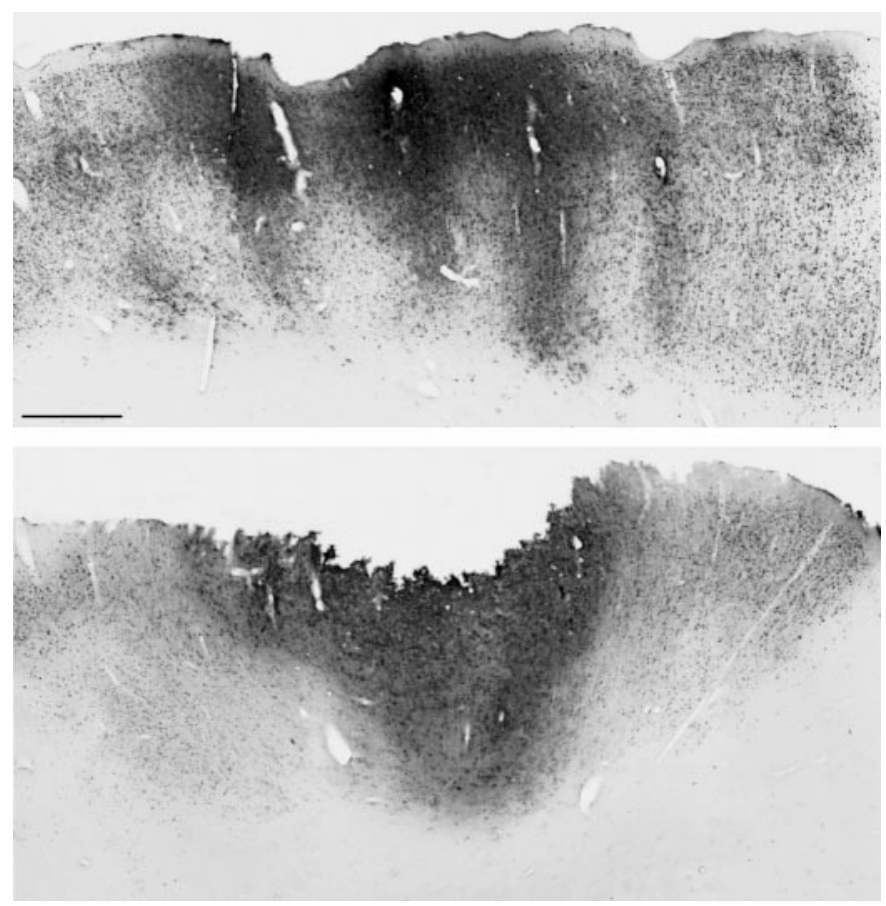

Figure 9. Examples of typical HSV1 injection sites in M1. The survival periods were $4-5 \mathrm{~d}$. Scale bar, $1 \mathrm{~mm}$.

In animal Jo 19, we placed multiple injections of HSV1 (McIntyre-B) into regions of the precentral gyrus and the anterior bank of the central sulcus, where intracortical stimulation evoked movements of the fingers, wrist, elbow, or shoulder (Figs. $10,11)$. A reconstruction of this area indicated that the injection 
Figure 10. Location of virus injections in arm M1 of animal Jo 19. A, Lateral view of the left hemisphere of the Cebus monkey. The enclosed area indicates the region of cortex enlarged in $B . B$, The region of M1 that was mapped by intracortical stimulation. Sites from which movements were evoked are marked with a letter designating the response observed (inset). Uppercase letters indicate sites where thresholds for movement were $\leq 10 \mu \mathrm{A}$. Lowercase letters indicate sites where thresholds were 11-35 $\mu \mathrm{A}$. Circles indicate where the microsyringe needle entered the surface of the cortex for virus injection. Squares indicate the point of entry for injections into the sulcus. The central sulcus has been opened to reveal its anterior bank. $C$, Coronal sections through the virus injection sites. The AP level of each section is indicated by the numbered arrows in $B$. The shaded areas in $B$ and $C$ indicate the spread of virus. $\mathrm{ArSi}$, Inferior limb of the arcuate sulcus; $\mathrm{ArSs}$, superior limb of the arcuate sulcus; $C$, caudal; $C S$, central sulcus; $D$, dorsal; $L$, lateral; $M$, medial.

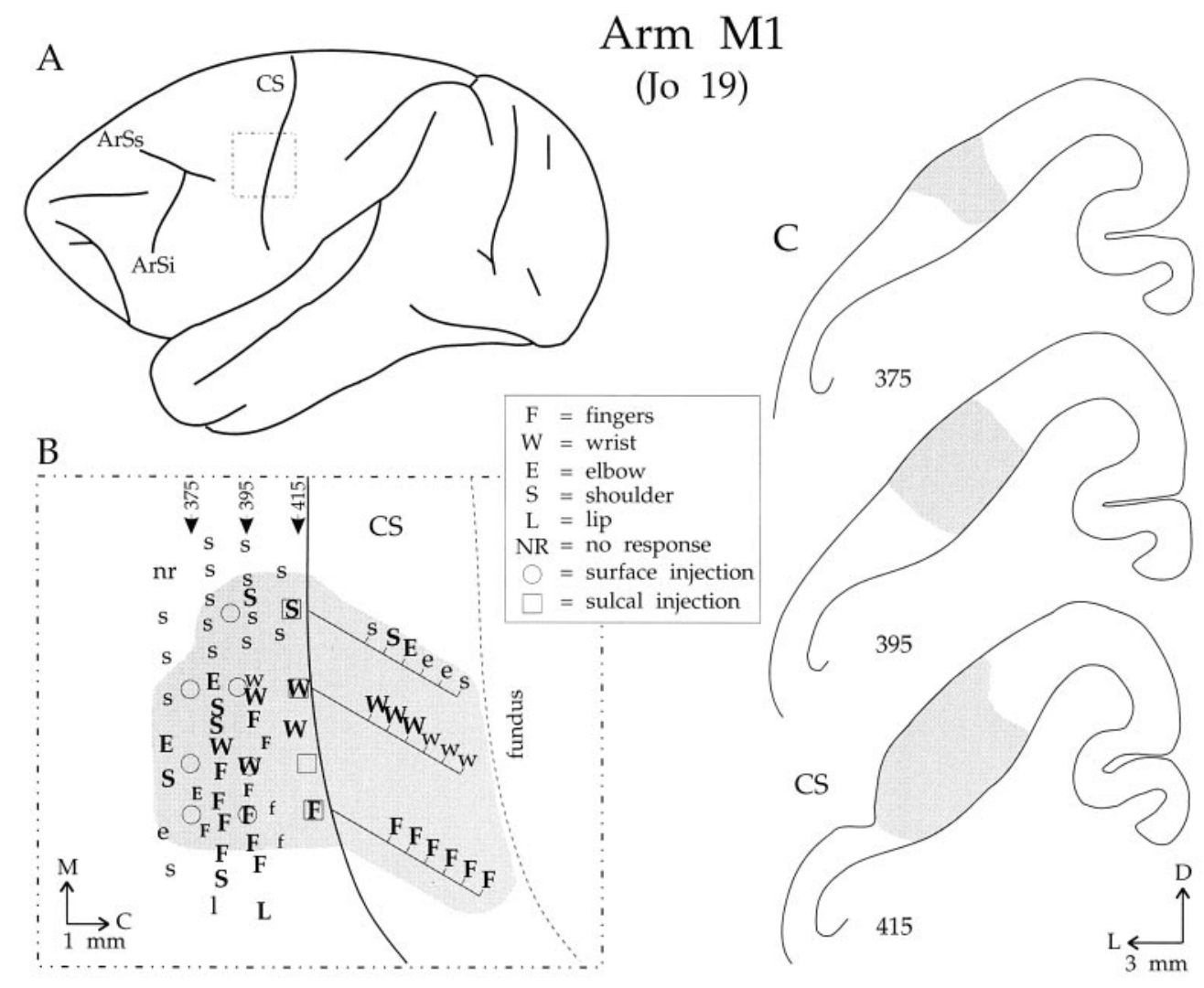

site involved a large portion of the arm representation of M1, without involving either the face or leg representations. We also mapped the arm representation of M1 in animal Jo 20. However, in this instance, we intentionally limited our injections to the hand area, where stimulation evoked movements of the fingers or wrist (Fig. 11). In animal Z10, injections of HSV1 (McIntyre-B) were placed into a portion of the arm representation identified by sulcal landmarks (Fig. 11). The injection site in Z10 was centered somewhat more medially than those in animals Jo 19 and Jo 20.

In animal Jo 17, HSV1 (McIntyre-B) was injected into a portion of the leg representation of M1 where stimulation evoked movements of the toes, knee, or hip (Fig. 12). The injection site in this animal was confined to a medial region of the precentral gyrus and did not spread laterally into the arm representation. In animal Jo 18, we injected virus into the face representation of M1, where stimulation evoked movements of the lips, tongue, or jaw (Fig. 13). The injection site in this animal was confined to a lateral region of the precentral gyrus and did not spread medially to involve the arm representation.

\section{Locations of transneuronally labeled neurons in the cerebellum (4-5d)}

Many labeled neurons (mean, 500; every third section examined) were found in the cerebellar deep nuclei in every animal that received injections of HSV1 (McIntyre-B) into M1 (Table 2). These labeled cells were located almost exclusively in the deep nuclei contralateral to the injected hemisphere. In each case, immunopositive neurons were found in portions of the anterior (NIA) and/or posterior interpositus nucleus (NIP) and the dentate nucleus (ND). Very few (range, 2-10; average, 4) labeled cells were observed in the fastigial nucleus (NF). These results indicate that the face, arm, and leg representations of M1 each

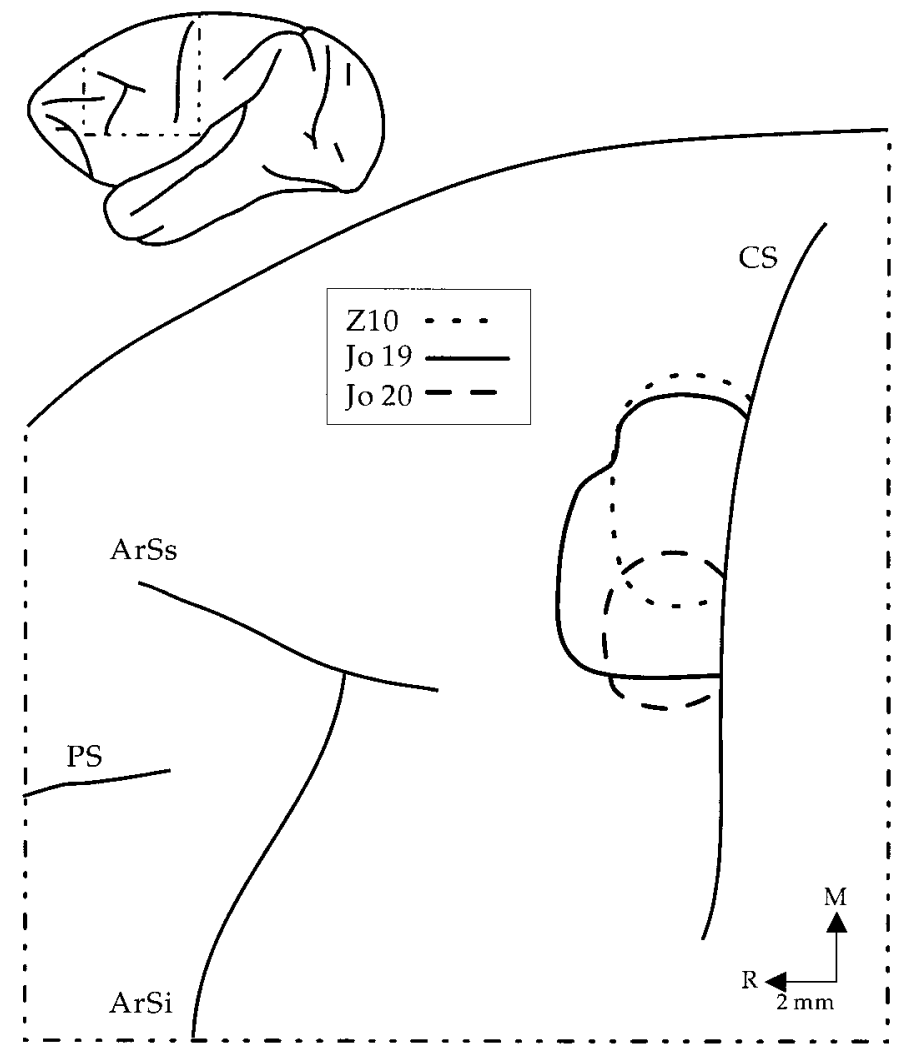

Figure 11. Relative locations of virus injection sites within arm M1 for three different animals (Z10, Jo 19, and Jo 20). ArSi, Inferior limb of the arcuate sulcus; $A r S s$, superior limb of the arcuate sulcus; $C S$, central sulcus; $M$, medial; $P S$, principal sulcus; $R$, rostral. 


\section{A}

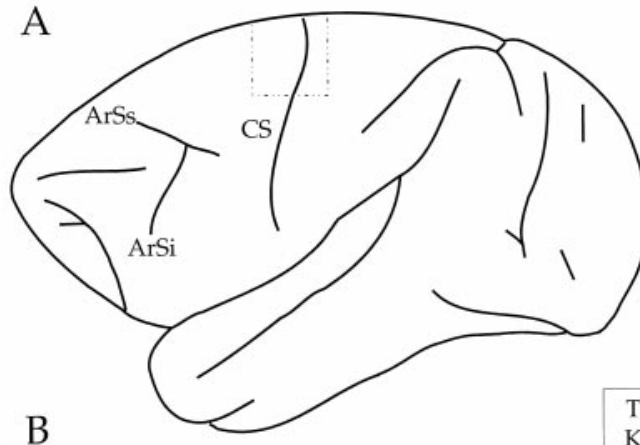

B

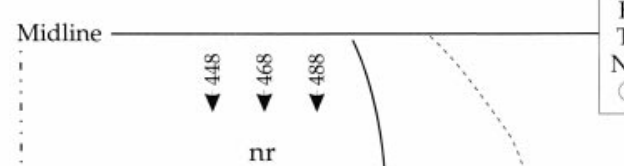

Leg M1

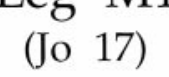

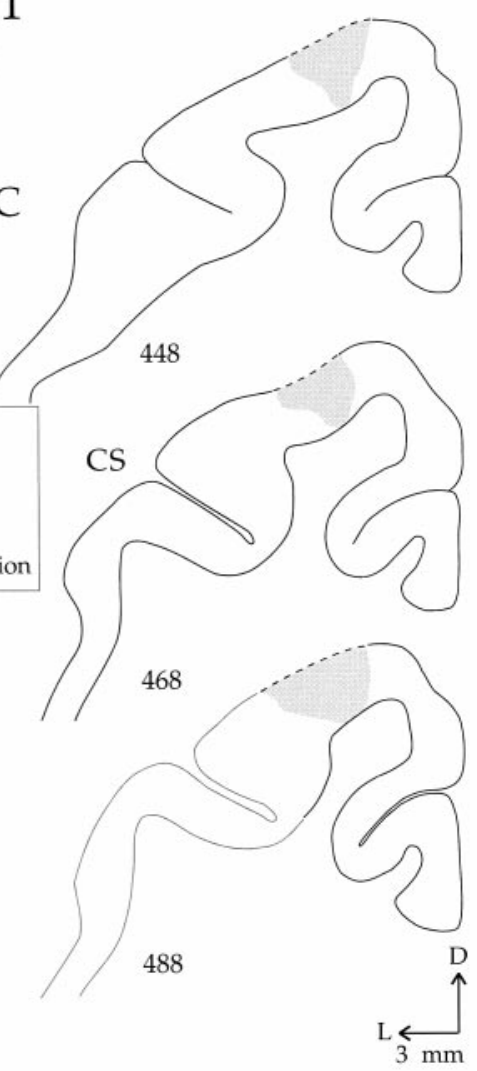

Figure 12. Location of virus injections in leg M1 of animal Jo 17. See Figure 10 for details. The dashed lines in $C$ represent areas of tissue loss. receive cerebellothalamocortical projections that originate from the NIA and/or NIP, and the ND, but only weakly from NF.

Most of the labeled cerebellar neurons were found in the dentate nucleus (Table 2). Their location within the dentate clearly varied depending on which somatotopic region of M1 was injected. Virus injections into the arm representation consistently labeled neurons in the middle third of the anteroposterior (AP) extent of the dentate (Fig. 14, top). Injections into the leg representation labeled neurons in the anterior third of the dentate, whereas injections into the face representation labeled neurons in the posterior third of the dentate (Fig. 15). Independent of the AP level, the labeled dentate neurons were concentrated in dorsal regions of the nucleus (Fig. 16). These observations provide evidence for the existence of a body map in the region of dentate nucleus that projects somatotopically to M1.

There also was evidence for a shift in the location of labeled neurons in the interpositus nuclei with different injection sites (Fig. 16). Virus injections into the arm area of M1 consistently led to labeled neurons in posterior portions of NIA and adjacent anterior portions of NIP. In contrast, injections into the leg area labeled neurons in anterior NIA, and injections into the face area labeled neurons in posterior NIP. These observations suggest that there is a body map within the interpositus nuclei that projects somatotopically to M1.

As noted above, the dentate nucleus provides the principal projection to all regions of M1. The number of labeled neurons in the dentate was consistently six times greater than that in the interpositus after HSV1 (McIntyre-B) injections into the arm area of M1 (Table 2). This disparity in the ratio of dentate to interpositus labeling was even greater after virus injections into the face area of M1 (ND:NI = 8:1). However, it was less after injection into the leg area (ND:NI = 3:1). These results suggest that there is a somatotopic variation in the relative contributions of dentate versus interpositus projections to M1.

\section{Locations of transneuronally labeled neurons in the basal ganglia $(4-5 d)$}

In addition to the labeled neurons observed in the cerebellar deep nuclei, many transneuronally labeled cells (mean, 436; every third section examined) were found in GPi (Table 2). We observed separate clusters of virus-infected neurons in the inner and outer portions of GPi in every experiment. In most animals, the labeled cells were located exclusively ipsilateral to the injected hemisphere. However, in the animal that received virus injections into face M1 (Jo 18), there was also a smaller number of neurons labeled in other areas of the basal ganglia (Table 2). These were located in dorsal regions of the ipsilateral substantia nigra pars reticulata (SNpr) and in ventrolateral regions of the contralateral GPi. These results indicate that the face, arm, and leg representations of M1 each receive basal ganglia-thalamocortical projections from GPi. Projections to the face area of M1 are bilaterally organized and emanate from the SNpr as well.

The location of labeled neurons within the ipsilateral GPi clearly varied depending on which somatotopic area of M1 was injected. This variation was greatest in the coronal plane (i.e., the dorsoventral dimension, Fig. 17). Virus injections into the face representation of M1 mainly labeled neurons in ventral and lateral regions of GPi. Injections into the leg representation labeled neurons in more dorsal and medial regions of GPi. Injections into the arm representation labeled an intermediate area of the nucleus.

There was also some variation in the location of labeled neu- 


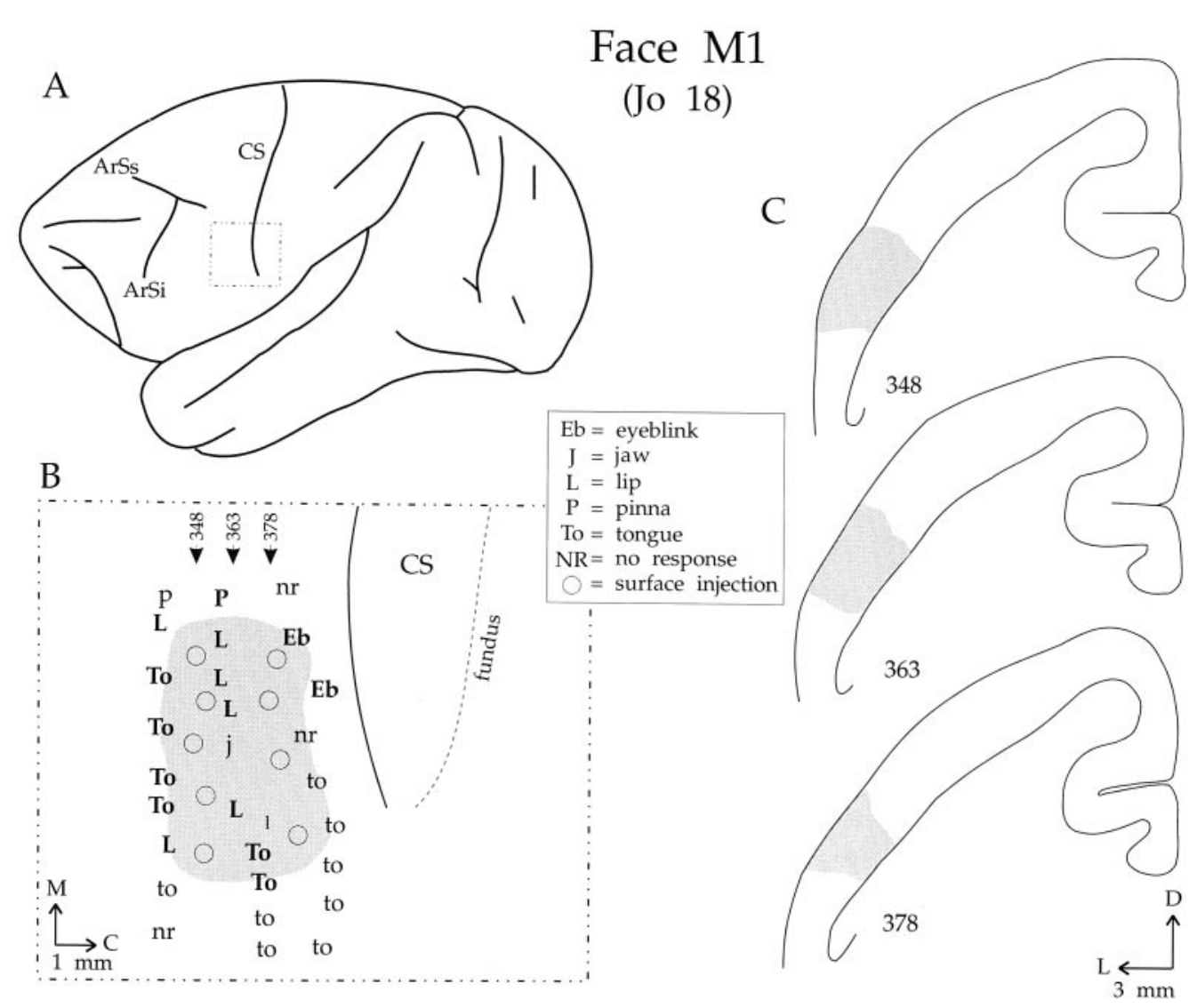

Figure 13. Location of virus injections in face M1 of animal Jo 18. See Figure 10 for details.
Overall, there appear to be genuine differences in the extent of basal ganglia and cerebellar input to different body representations in M1 and even local differences within the map of a single body representation.

\section{Estimations of volume}

We performed an ad hoc analysis using Cavalieri's estimator of morphometric volume to determine the proportion of the dentate and GPi that is directed to M1. When we calculated the total volume of the dentate occupied by neurons that project to the face, arm, and leg regions of M1 (Table 3), we found that this represents $\sim 30 \%$ of the nucleus. Less than $15 \%$ of the volume of GPi was found to project to the face, arm, and leg representations of M1. These results lead us to conclude that, although the dentate and GPi project somatotopically on M1, the majority of the output from these two subcortical nuclei is directed to other areas of the brain. This conclusion is supported by our findings that some of the regions in dentate and GPi that were unlabeled after virus injections in M1 project to premotor and prefrontal cortex (Hoover and Strick, 1993b; Strick et al., 1993; Lynch et al., 1994; Middleton and Strick, 1994, 1997, 1998).

\section{DISCUSSION}

\section{Methodological issues}

Before discussing the functional implications of our results, we will address several methodological issues concerning the use of herpes viruses as transneuronal tracers. The effective use of viruses in neuroanatomical studies is predicated on the answers to four major questions: (1) What is the direction of transport, and is this pathway dependent? (2) What is the time course of transport? (3) Does transneuronal transport occur exclusively at sites imply that other regions within the area covered by the large injection site receive more basal ganglia than cerebellar input. injection site (in animal Jo 20), which was largely limited to the hand area of M1, labeled more than twice as many cerebellar as basal ganglia neurons. The injection site in Jo 20 was almost entirely included within that of Jo 19 (Fig. 11). These results 
Table 2. The number of transneuronally labeled neurons observed in the output nuclei of the cerebellum and basal ganglia 4-5 $\mathrm{d}$ after injections of HSV-1 into the primary motor cortex

\begin{tabular}{llllllll} 
& $\begin{array}{l}\text { Region } \\
\text { of M1 } \\
\text { injected }\end{array}$ & $\begin{array}{l}\text { \# of labeled } \\
\text { cells in ND }\end{array}$ & $\begin{array}{l}\text { \# of labeled } \\
\text { cells in NI }\end{array}$ & $\begin{array}{l}\text { ND:NI } \\
\text { ratio }\end{array}$ & $\begin{array}{l}\text { \# of la- } \\
\text { beled cells } \\
\text { in ipsi GPi }\end{array}$ & $\begin{array}{l}\text { \# of labeled } \\
\text { cells in contra } \\
\text { GPi }\end{array}$ & $\begin{array}{l}\text { \# of labeled } \\
\text { cells in ipsi } \\
\text { SNpr }\end{array}$ \\
\hline Z10 & Arm & 513 & 86 & $6.0: 1.0$ & 475 & $\begin{array}{l}\text { Cerebellum: } \\
\text { basal ganglia } \\
\text { ratio }\end{array}$ \\
Jo 19 & Arm & 547 & 85 & $6.4: 1.0$ & 630 & & $1.3: 1.0$ \\
Jo 20 & Arm & 270 & 42 & $6.4: 1.0$ & 152 & & $1.0: 1.0$ \\
Jo 17 & Leg & 425 & 138 & $3.1: 1.0$ & 273 & & $2.1: 1.0$ \\
Jo 18 & Face & 348 & 43 & $8.1: 1.0$ & 652 & 74 & 42.1 .0 \\
\hline
\end{tabular}

where neurons are synaptically connected? (4) Does transneuronal transport occur at all synapses, or is it limited to only specific sets of synaptically interconnected cells? The answers to these questions are clearly dependent not only on the specific neurotropic virus used, but also on a number of other important factors, such as the precise strain of virus and its titer, the animal species used, the age, strain, and immunocompetence of the animal, and the site and route of inoculation (for review, see Strick and Card, 1992).

A number of observations indicate that the distribution of labeled neurons seen after transport of the McIntyre-B strain of HSV1 in the cebus monkey accurately reflects patterns of neuronal connections. First, our results demonstrate that this strain of HSV1 is selectively transported in the retrograde direction, effectively labeling all known inputs to a cortical injection site. The distribution of thalamic neurons infected with virus 2-3 d after
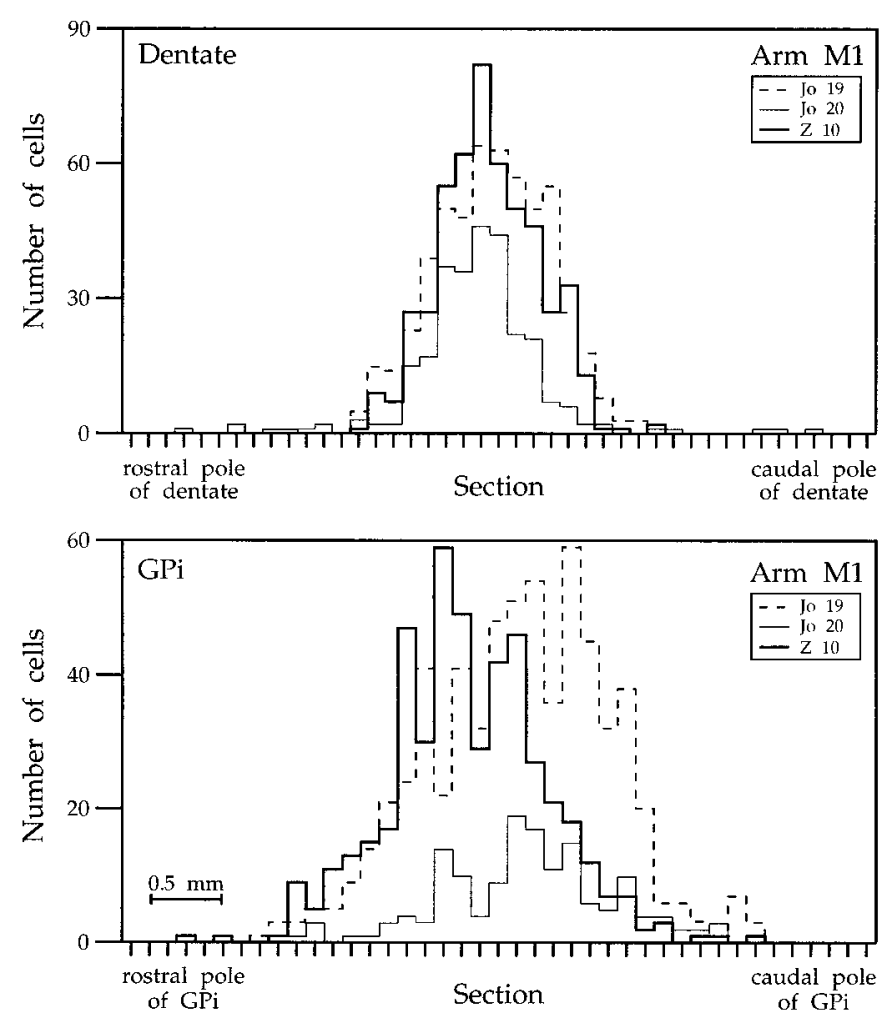

Figure 14. Rostrocaudal distributions of labeled neurons in three animals with virus injections into arm M1. Top, Histograms of labeled neurons in dentate. Bottom, Histograms of labeled neurons in GPi. The height of the columns indicates the number of labeled neurons observed in each tissue section. cortical injections matched the patterns of thalamic labeling seen after cortical injections of a conventional tracer (WGA-HRP). Second, our findings show that the McIntyre-B strain of HSV1, at the concentrations we used, requires $\sim 2.5 \mathrm{~d}$ for transneuronal transport from one site to another. In experiments in which we examined the organization of cerebellar and basal ganglia outputs to M1, this time course enabled us to set the survival time to allow labeling of second- but not third-order neurons. Third, our observations suggest that the patterns of labeling seen at survival times $>2-3 \mathrm{~d}$ are caused by transsynaptic transport of virus. Others have argued that the cellular lysis seen in later stages of HSV1 infection permits nonsynaptic transfer of virus (Ugolini, 1995). At least at the survival times we used, our results argue against this view. We observed an orderly point-to-point correspondence between the location of cortical injections (i.e., face, arm, or leg M1) and the spatial pattern of transneuronal labeling at subcortical sites. It is unlikely that such well defined patterns of labeling could result from transfer of virus through nonspecific release into the extracellular space. Perhaps more importantly, we found that transneuronal transfer of the virus precedes any significant neuronal lysis. Others have reported similar results with a swine $\alpha$ herpes virus (Rinamen et al., 1993; Card et al., 1995; O’Donnell et al., 1997). Furthermore, in experiments using injections of rabies virus into M1, we have seen similar patterns of transneuronal transport in the absence of any cellular destruction (Kelly and Strick, 1997). Last, our findings suggest that the transneuronal transfer of HSV1 is not restricted to a specific set of synaptic connections. We observed robust transneuronal labeling in both cerebellar and pallidal circuits, although the types of synapses made by cerebellar and pallidal efferents on thalamic neurons are very different (Jones, 1985). Moreover, in other experiments, we have shown that transneuronal transport of the McIntyre-B strain of HSV1 occurs through all the known subcortical outputs to the frontal eye field, including such diverse systems as those from the substantia nigra, dentate nucleus, and superior colliculus (Lynch et al., 1994).

One final methodological concern is the identification of the thalamic nuclei that mediate transneuronal transport of HSV1 from M1 to the cerebellar deep nuclei and GPi. Both cerebellar and pallidal efferents project not only to subdivisions of the ventrolateral thalamus but also to midline and intralaminar nuclei (Percheron, 1977; Stanton, 1980; Kalil, 1981; DeVito and Anderson, 1982; Asanuma et al., 1983; Ilinsky and Kultas-Ilinsky, 1987; Sakai et al., 1996; Sidibe et al., 1997). All of these thalamic regions project to M1 (Matelli et al., 1989; Darian-Smith et al., 1990; Holsapple et al., 1991; Rouiller et al., 1994; Stepniewska et al., 1994; Inase and Tanji, 1995; Shindo et al., 1995). Consequently, all of them could provide a route for the cerebellar and pallidal 
Figure 15. Histograms of the distribution of labeled neurons in dentate after virus injections into leg (Jo 17, top), arm (Jo 19 , middle), or face (Jo 18, bottom) M1. The numbers highlighted on the abscissae correspond to the sections illustrated in Figure 16.
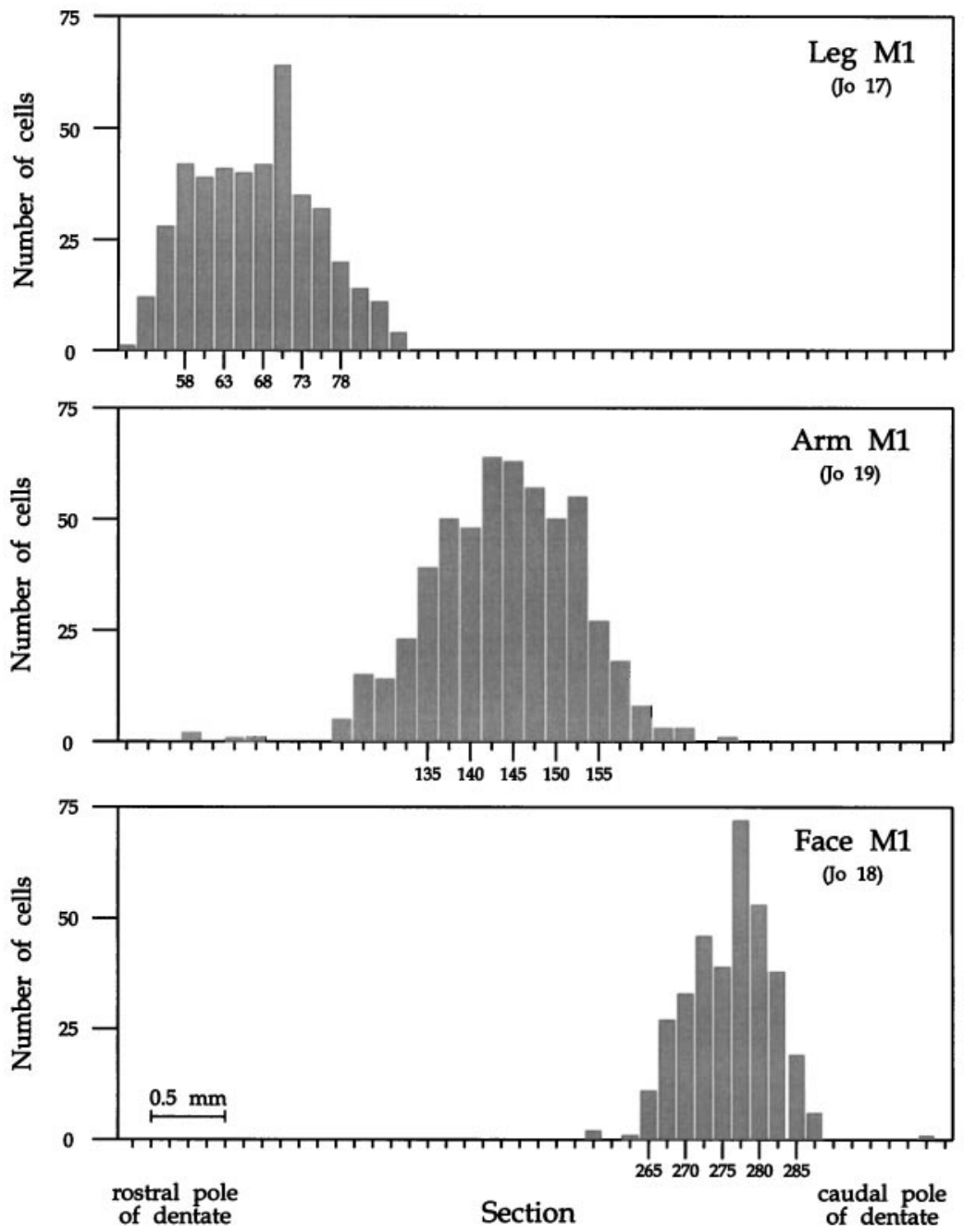

labeling we observed. However, for the remainder of the Discussion, we will assume that the majority of the labeled neurons at subcortical sites reflect transneuronal transport via the ventrolateral thalamus. This view is based on observations with conventional tracers that show that most $(>80 \%)$ of the thalamic input to $\mathrm{M} 1$ originates from the ventrolateral thalamus, whereas only a weak contribution comes from the midline and intralaminar nuclei (Darian-Smith et al., 1990; Holsapple et al., 1991; Stepniewska et al., 1994). Thus, although M1 receives input from multiple thalamic nuclei, its predominant input is from the ventrolateral thalamus, and the cerebellar and pallidal labeling is likely to reflect this predominance.

\section{Functional implications}

Sources of cerebellar and basal ganglia projections to M1

Our results provide new insights into the organization of the circuits that link cerebellar and basal ganglia outputs with M1. It is generally agreed that efferents from the cerebellar deep nuclei terminate in subdivisions of the ventrolateral thalamus that innervate M1 (Percheron, 1977; Stanton, 1980; Kalil, 1981; Asanuma et al., 1983; Rouiller et al., 1994; Sakai et al., 1996). Whether all three cerebellar deep nuclei contribute to this pathway has been unclear (Asanuma et al., 1983, their Fig. 21). Our findings indicate that the majority $(75-90 \%)$ of the cerebellar output to the face, arm, and leg representations of M1 originate from the dentate nucleus. In contrast, the two portions of interpositus contribute only $10-25 \%$ of the cerebellar output, depending on the region of M1 examined, and very little output originates from the fastigial nucleus.

The organization of basal ganglia projections to M1 has been the subject of some controversy. Although it is well established that pallidal and nigral efferents terminate in several subdivisions of the ventrolateral thalamus (Kuo and Carpenter, 1973; Carpenter et al., 1976; Kim et al., 1976; DeVito and Anderson, 1982; Ilinsky et al., 1993; Rouiller et al., 1994; Sakai et al., 1996), the density and even the existence of projections from these subdivisions to M1 have been questioned (for review, see Matelli et al., 1989; Holsapple et al., 1991; Inase and Tanji, 1995). Our observations clearly demonstrate that the face, arm, and leg representations of M1 are the target of basal ganglia output (for electrophysiological evidence, see Nambu et al., 1988, 1990, 1991; Jinnai et al., 1993). In fact, on average, the number of neurons labeled in the output nuclei of the basal ganglia was as substantial as that labeled in the cerebellar deep nuclei (Table 2). This result suggests that, overall, basal ganglia projections to M1 are as prominent as those from the cerebellum. On the other hand, our observations also support the concept that M1 is not homogeneous in terms of its inputs (Matelli et al., 1989; Holsapple et al., 1991). We found that some localized regions within M1 receive 
Leg MC

(Jo 17)

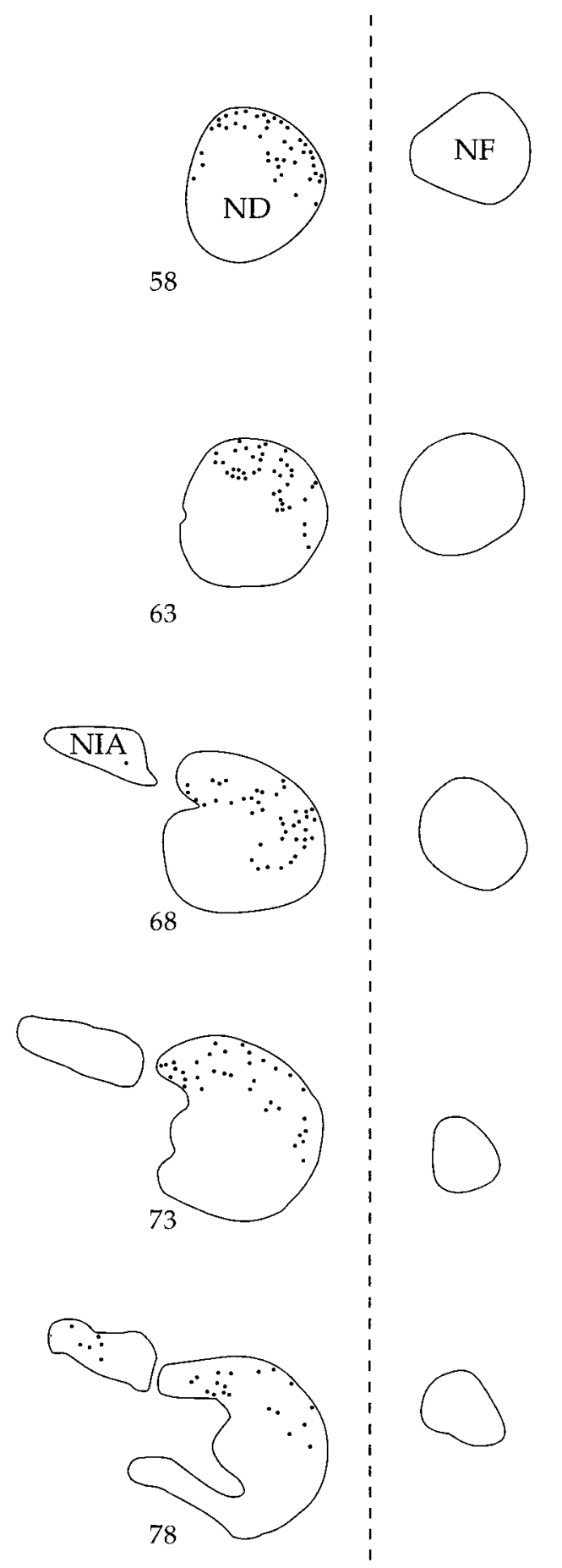

Arm M1

(Jo 19)
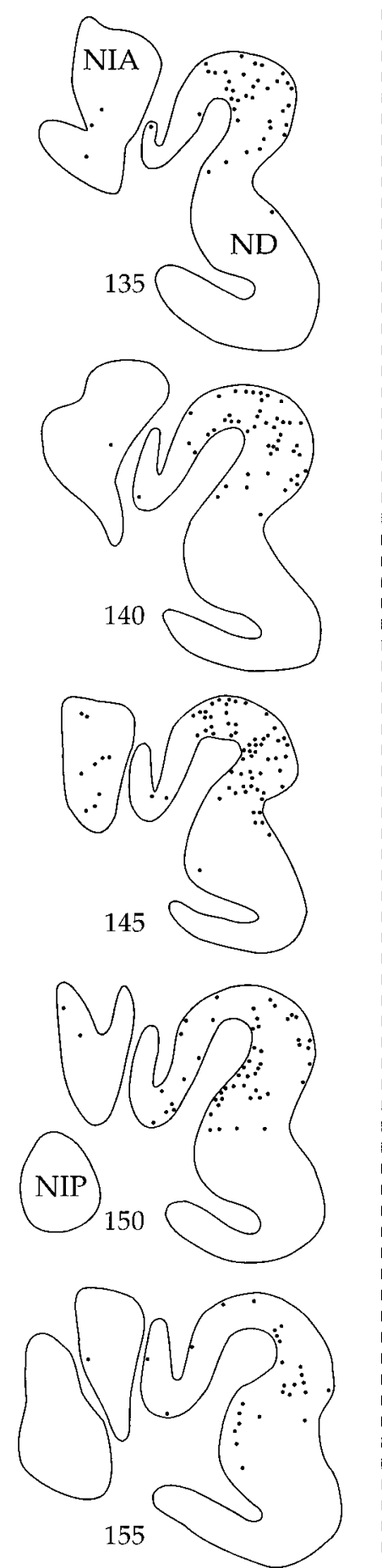

Face M1

(Jo 18)

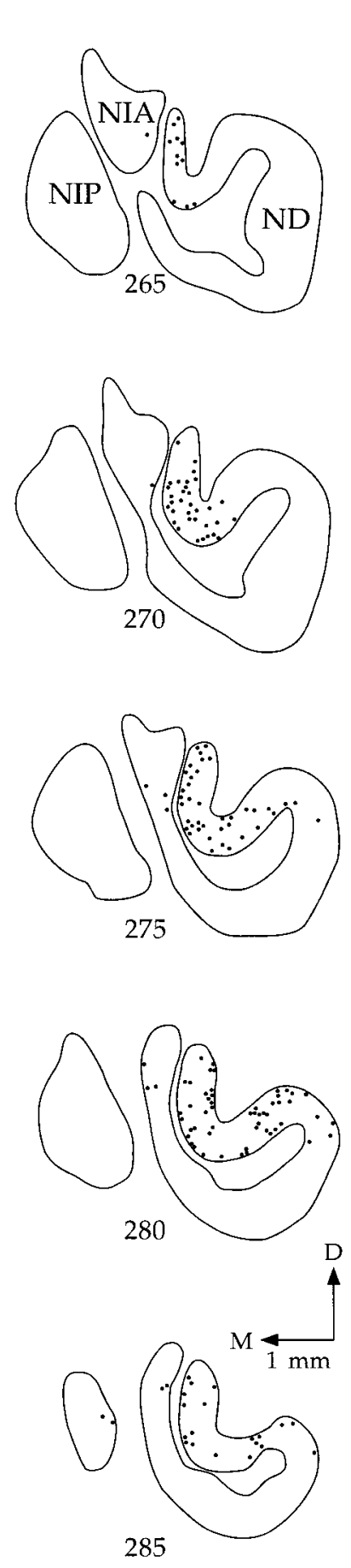

Figure 16. Plots of labeled cells in the cerebellar deep nuclei. Each dot represents the position of a neuron labeled by transneuronal transport of virus from leg (Jo 17, left), arm (Jo 19, middle), or face (Jo 18, right) M1. D, Dorsal; $M$, medial; ND, dentate nucleus; NIA, anterior interpositus nucleus; NIP, posterior interpositus nucleus; $N F$, fastigial nucleus.

more input from the cerebellum than from the basal ganglia, whereas the opposite is true at other sites within M1.

These results raise a number of intriguing questions. For example, what is the functional significance of a region in M1 receiving more of one subcortical output than another? What mapping principle governs the differential distribution of cerebellar and basal ganglia outputs to M1? Is there a difference in the subcortical projections to proximal and distal limb representations in M1 or even within different parts of the distal representation? Do cerebellar and basal ganglia projections to M1 termi- 

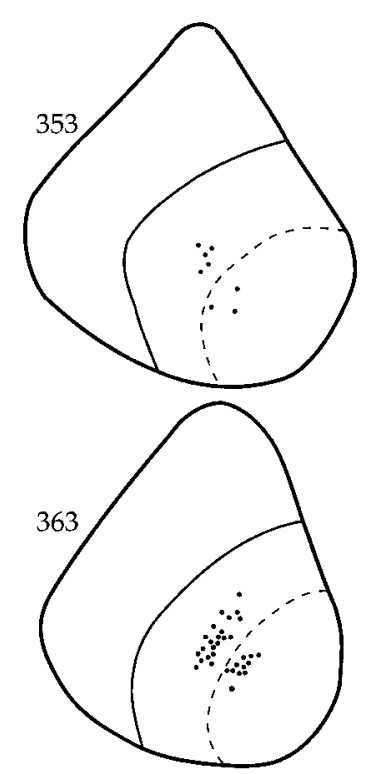

Figure 17. Plots of labeled cells in the globus pallidus. Each dot represents the position of a neuron labeled by transneuronal transport of virus from leg (Jo 17, left), arm (Jo 19, middle), or face (Jo 18, right) M1. The section numbers correspond to those highlighted on the abscissae of Figure 18. D, Dorsal; $G P e$, external segment of GP; $G P i_{\mathrm{i}}$, inner portion of the internal segment of GP; $G P i_{\mathrm{o}}$, outer portion of the internal segment of GP; $M$, medial.
Leg M1

(Jo 17)
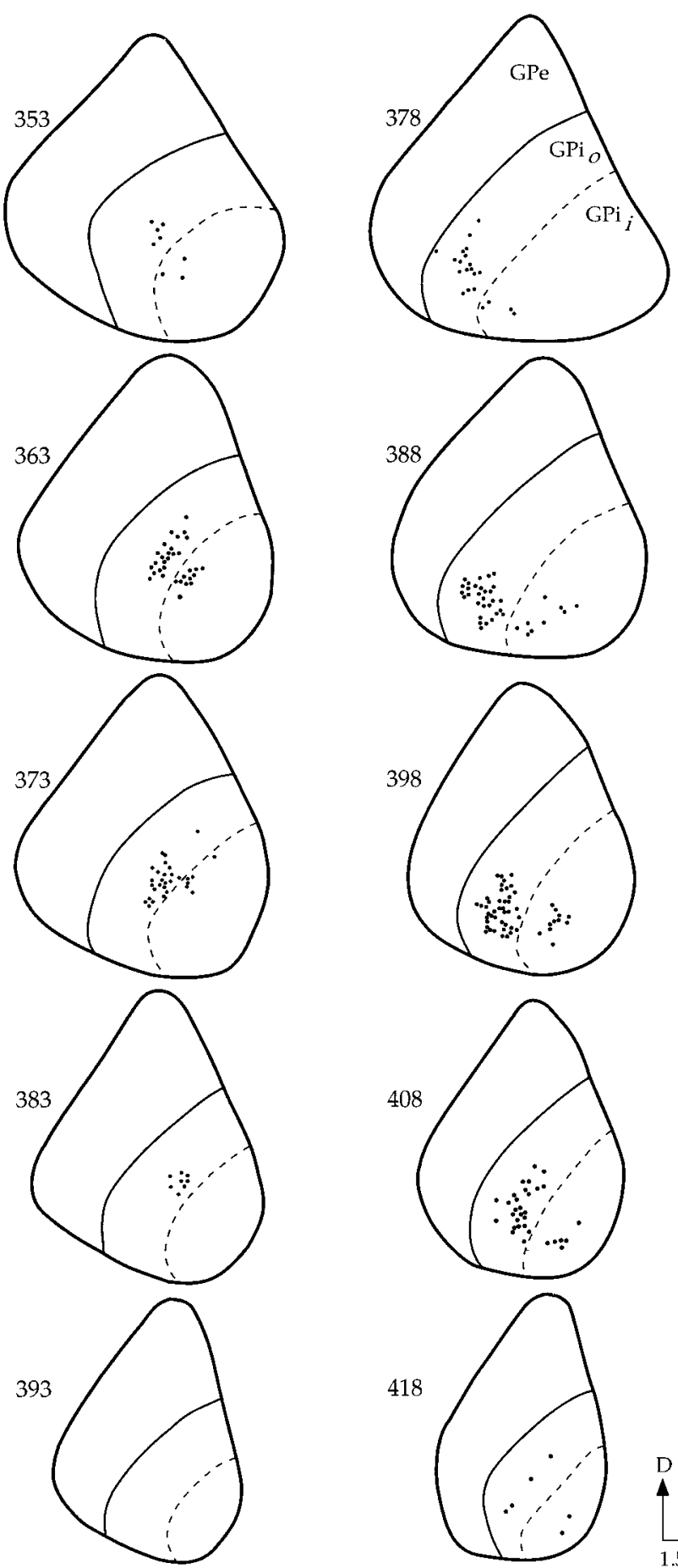

Arm M1

(Jo 19)

Face M1

(Jo 18)
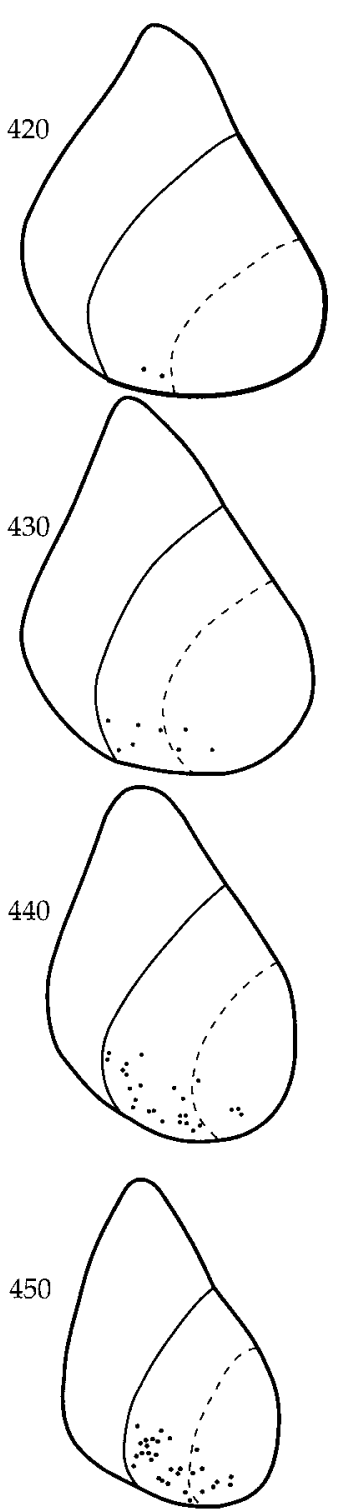

418
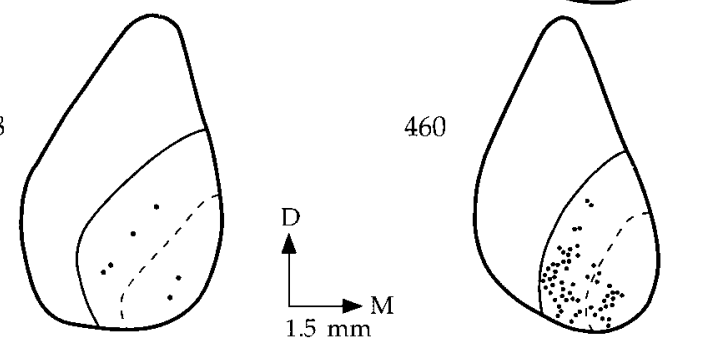

nate in discrete bands or patches? If so, do these overlap and/or interdigitate? Some of these questions could be addressed using smaller injections of the McIntyre-B strain of HSV1 into physiologically mapped regions of M1. Other experiments could include an analysis of the distribution of labeled neurons in M1 after anterograde transneuronal transport of the H129 strain of HSV1 (Zemanick et al., 1991) from the output nuclei of the cerebellum and basal ganglia. Whatever the outcome of such

experiments, our results clearly indicate that both the cerebellum and basal ganglia have a complex pattern of projections on M1.

\section{Body maps}

Several anatomical and physiological studies have attempted to define the patterns of body representation within the output nuclei of the cerebellum and basal ganglia (Rispal-Padel, 1982; Asanuma et al., 1983; DeLong et al., 1983, 1985; Nambu et al., 

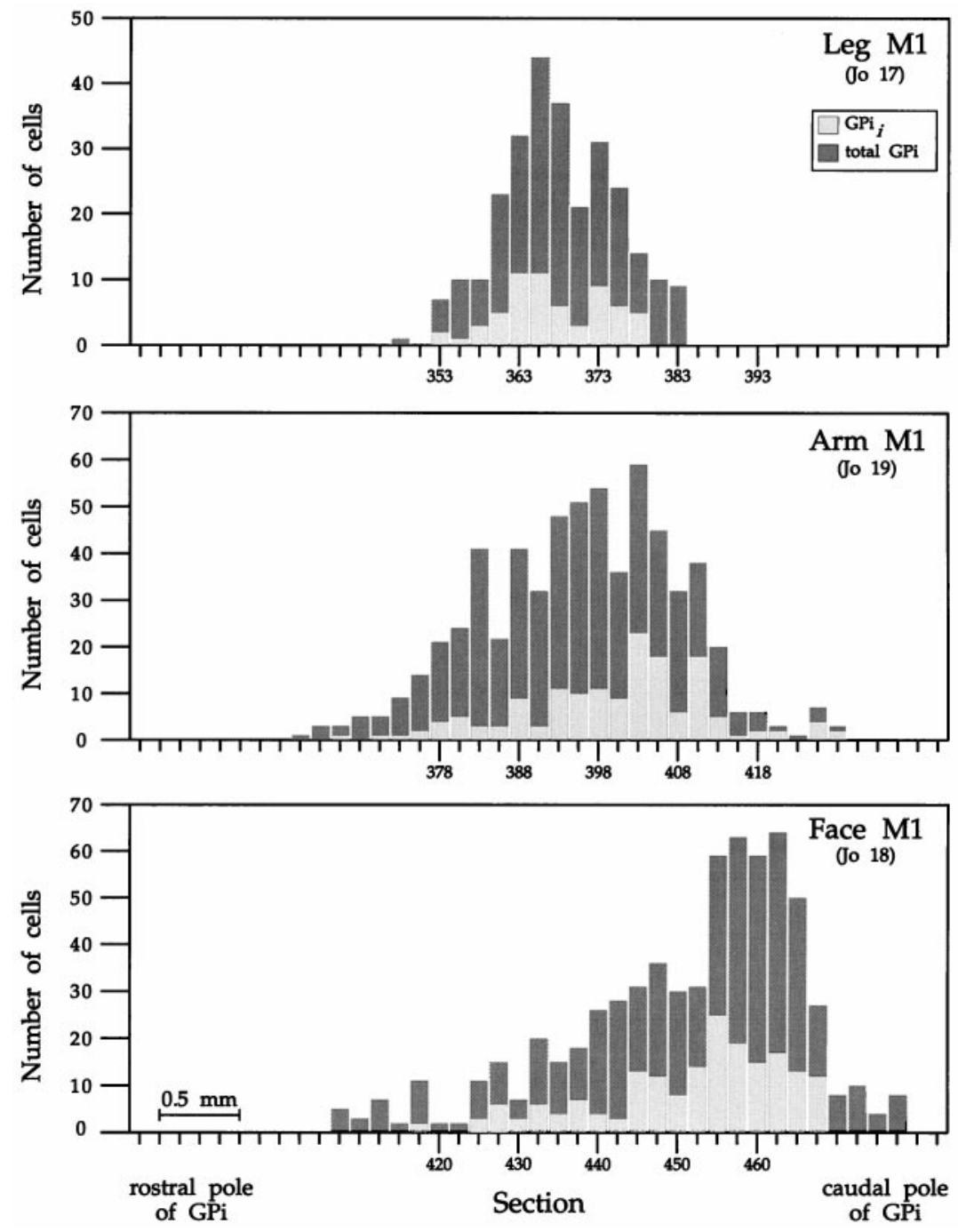

Figure 18. Histograms of the distribution of labeled neurons in GPi after virus injections into leg (Jo 17, top), arm (Jo 19, middle), or face (Jo 18, bottom) M1. The height of the light and dark stippling indicates the proportion of labeled cells observed in the inner portion of GPi and all of GPi (inset).
1990; Thach et al., 1993; van Kan et al., 1993). With regard to the cerebellum, there is general agreement that the dentate contains at least one rostrocaudally oriented body map, with the leg represented rostrally in the nucleus, face caudally, and the arm at intermediate levels. Our results support this general view. On the other hand, Asanuma et al. (1983) concluded that the dentate

\begin{tabular}{|c|c|c|c|}
\hline & $\begin{array}{l}\text { Jo } 17 \\
\text { (Leg M1) }\end{array}$ & $\begin{array}{l}\text { Jo } 19 \\
\text { (Arm M1) }\end{array}$ & $\begin{array}{l}\text { Jo } 18 \\
\text { (Face M1) }\end{array}$ \\
\hline $\begin{array}{l}\text { Volume of ND directed } \\
\text { to } \mathrm{M} 1\left(\mathrm{~mm}^{3}\right)\end{array}$ & 2.0 & 3.0 & 1.2 \\
\hline $\begin{array}{l}\text { Volume of entire ND } \\
\left(\mathrm{mm}^{3}\right)\end{array}$ & 19.8 & 22.8 & 18.6 \\
\hline $\begin{array}{l}\text { Percentage of ND di- } \\
\text { rected to M1 }\end{array}$ & 10.1 & 13.2 & 6.4 \\
\hline $\begin{array}{l}\text { Volume of GPi directed } \\
\text { to } \mathrm{M} 1\left(\mathrm{~mm}^{3}\right)\end{array}$ & 1.2 & 3.5 & 3.4 \\
\hline $\begin{array}{l}\text { Volume of entire GPi } \\
\left(\mathrm{mm}^{3}\right)\end{array}$ & 42.7 & 65.8 & 62.2 \\
\hline $\begin{array}{l}\text { Percentage of GPi di- } \\
\text { rected to M1 }\end{array}$ & 2.8 & 5.3 & 5.5 \\
\hline
\end{tabular}

contained a single body map that filled the nucleus. This conclusion was based on their analysis of dentate terminations in the thalamus and hypotheses about the organization of thalamocortical projections to M1. Retrograde transneuronal transport of HSV1 allowed us to examine the dentatothalamocortical circuit in a single experiment. Our results indicate that, for all body parts examined, the projection to M1 originates from approximately the dorsal third of the nucleus. Admittedly, our virus injection sites did not completely fill the face and leg representations of M1. However, our injections into the arm representation were extensive, and yet labeled neurons were found only in dorsal portions of the dentate. Furthermore, additional experiments from this laboratory have demonstrated that more ventral regions of the dentate project to cortical areas other than M1 (Strick et al., 1993; Lynch et al., 1994; Middleton and Strick, 1994, 1997). Thus, taken together, our results suggest that the dentate contains multiple maps of the body and that the map defined by its connections with M1 is limited to the dorsal third of the nucleus.

Our results also support the presence of a separate body map in the interpositus nucleus. The projection to the leg representation of M1 originates from rostral NIA and the projection to the face representation from caudal NIP. The projection to the arm representation originates from a caudal portion of NIA and an adjacent rostral portion of NIP (see also Mason et al., 1998). 
Thus, our data indicate that the regions of interpositus that project to M1 contain a single body map that spans both subdivisions of the nucleus.

The results of physiological studies have suggested that the pattern of body representation in the output nuclei of the basal ganglia is more complex than that in the cerebellum. For example, DeLong et al. $(1983,1985)$ demonstrated that the orofacial representation is divided between posteroventral portions of GPi and adjacent regions of SNpr. Our results on the origin of projections to the face representation of M1 support this finding. The physiological studies also reported other general trends in body representation. However, these trends were confounded by the observation that clusters of neurons related to arm movements were intermingled with clusters of neurons related to face or leg movements (DeLong et al., 1985; Hamada et al., 1990; Mink and Thach, 1991). We have shown in other experiments that the basal ganglia contain multiple, spatially separate, output channels that project to different cortical motor areas. Each of these output channels is likely to have its own body map. Therefore, we believe that the intermingling observed in the physiological studies was largely caused by the fact that recordings were made from more than one output channel. In fact, in the present experiments, we examined the organization of a single output channel, the one to M1, and found that the pattern of body representation within it was no more or less complicated than that within cerebellar systems.

\section{Proportion of nuclear volume devoted to M1}

Although our study clearly demonstrates that M1 is the target of both cerebellar and basal ganglia output, it is surprising how small a proportion of cerebellar and basal ganglia volume is devoted to this purpose. We found that only $30 \%$ of the dentate volume is directed to M1. Similarly, only $15 \%$ of GPi innervates M1. If one considers that basal ganglia output also originates from parts of the substantia nigra and ventral pallidum, this figure is probably an overestimate.

It should be recognized that the percentages cited above are only approximations. These could be influenced by a number of technical factors such as the size of the injection sites and the effective zone of uptake for retrograde transneuronal transport. As a consequence, it is likely that some of the cerebellar or basal ganglia cells that project to M1 were not labeled in our experiments. On the other hand, we have shown in other studies that the output nuclei of the cerebellum and basal ganglia project not only to M1, but also to a variety of cortical areas including several premotor areas, regions in prefrontal cortex, and portions of inferotemporal cortex (Hoover and Strick, 1993b; Lynch et al., 1994; Middleton and Strick, 1994, 1996, 1997, 1998). The projections to these additional cortical areas originate from portions of the two output nuclei that were unlabeled after virus injections into M1. These results, along with our volume measurements, suggest that a major fraction of the output from the cerebellum and basal ganglia is directed to cortical areas other than M1. It is important to note that our results do not preclude the possibility that, of all the cortical areas, M1 receives the largest proportion of cerebellar or basal ganglia output. Experiments in progress are seeking to define all of the cortical targets of basal ganglia and cerebellar output and will evaluate this possibility.

\section{REFERENCES}

Asanuma C, Thach WT, Jones EG (1983) Anatomical evidence for segregated focal groupings of efferent cells and their terminal ramifi- cations in the cerebellothalamic pathway of the monkey. Brain Res Rev 5:267-297.

Brooks VB, Thach WT (1981) Cerebellar control of posture and movement. In: Handbook of physiology, section 1: the nervous system, Vol 2, motor control (Brooks VB, ed), pp 877-946. Bethesda, MD: American Physiological Society.

Card JP, Dubin JR, Whealy ME, Enquist LW (1995) Influence of infectious dose upon productive replication and trans-synaptic passage of pseudorabies virus in rat central nervous system. J Neurovirol 1:349-358.

Carpenter MB, Nakano K, Kim R (1976) Nigrothalamic projections in the monkey demonstrated by autoradiographic technics. J Comp Neurol 165:401-416.

Darian-Smith C, Darian-Smith I, Cheema SS (1990) Thalamic projections to sensorimotor cortex in the macaque monkey: use of multiple retrograde fluorescent tracers. J Comp Neurol 299:17-46.

DeLong MR, Georgopoulos AP (1981) Motor functions of the basal ganglia. In: Handbook of physiology, section 1: the nervous system, Vol 2, motor control (Brooks VB, ed), pp 1017-1061. Bethesda, MD: American Physiological Society.

DeLong MR, Crutcher MD, Georgopoulos AP (1983) Relations between movement and single cell discharge in the substantia nigra of the behaving monkey. J Neurosci 3:1599-1606.

DeLong MR, Crutcher MD, Georgopoulos AP (1985) Primate globus pallidus and subthalamic nucleus: functional organization. J Neurophysiol 53:530-543.

DeVito JL, Anderson ME (1982) An autoradiographic study of efferent connections of the globus pallidus in Macaca mulatta. Exp Brain Res 46:107-117.

Dix RD, McKendall RR, Baringer JR (1983) Comparative neurovirulence of herpes simplex virus type 1 strains after peripheral or intracerebral inoculation of BALB/c mice. Infect Immun 40:103-112.

Dum RP, Strick PL (1991) Premotor areas: nodal points for parallel efferent systems involved in the central control of movement. In: Motor control: concepts and issues (Humphrey DR, Freund H-J, eds), pp 383-397. London: Wiley.

Eager RP (1966) Patterns and mode of termination of cerebellar corticonuclear pathways in the monkey (Macaca mulatta). J Comp Neurol 126:551-566.

Flaherty AW, Graybiel AM (1993) Output architecture of the primate putamen. J Neurosci 13:3222-3237.

Flaherty AW, Graybiel AM (1994) Input-output organization of the sensorimotor striatum in the squirrel monkey. J Neurosci 14:599-610.

Gibson AR, Hansma DI, Houk JC, Robinson FR (1984) A sensitive low artifact TMB procedure for the demonstration of WGA-HRP in the CNS. Brain Res 298:235-241.

Hamada I, DeLong MR, Mano N-I (1990) Activity of identified wristrelated pallidal neurons during step and ramp wrist movements in the monkey. J Neurophysiol 64:1892-1906.

Hazrati L-N, Parent A (1992) The striatopallidal projection displays a high degree of anatomical specificity in the primate. Brain Res 592:213-227.

Hazrati L-N, Parent A, Mitchell S, Haber SN (1990) Evidence for interconnections between the two segments of the globus pallidus in primates: a PHA-L anterograde tracing study. Brain Res 533:171-175.

Holsapple JW, Preston JB, Strick PL (1991) The origin of thalamic inputs to the "hand" representation in the primary motor cortex. J Neurosci 11:2644-2654.

Hoover JE, Strick PL (1992) Cerebello- and pallido-thalamocortical projections to the primary motor cortex: body maps. Soc Neurosci Abstr 18:309.

Hoover JE, Strick PL (1993a) Retrograde transneuronal transport of HSV-1 from primary motor cortex to cerebellar deep nuclei and Purkinje cells. Soc Neurosci Abstr 19:1590.

Hoover JE, Strick PL (1993b) Multiple output channels in the basal ganglia. Science 259:819-821.

Ilinsky IA, Kultas-Ilinsky K (1987) Sagittal cytoarchitectonic maps of the Macaca mulatta thalamus with a revised nomenclature of the motor-related nuclei validated by observations on their connectivity. J Comp Neurol 262:331-364.

Ilinsky IA, Tourtellotte G, Kultas-Ilinsky K (1993) Anatomical distinctions between the two basal ganglia afferent territories in the primate motor thalamus. Stereotactic Funct Neurosurg 60:62-69.

Inase M, Tanji J (1995) Thalamic distribution of projection neurons to 
the primary motor cortex relative to afferent terminal fields from the globus pallidus in the macaque monkey. J Comp Neurol 353:415-426.

Jinnai K, Nambu A, Tanibuch I, Yoshida S (1993) Cerebello- and pallido-thalamic pathways to areas 6 and 4 in the monkey. Stereotactic Funct Neurosurg 60:70-79.

Jones EG (1985) The thalamus. New York: Plenum.

Kalil K (1981) Projections of the cerebellar and dorsal column nuclei upon the thalamus of the rhesus monkey. J Comp Neurol 195:25-50.

Kayahara T, Nakano K (1996) Pallido-thalamo-motor cortical connections: an electron microscopic study in the macaque monkey. Brain Res 706:337-342.

Kelly RM, Strick PL (1997) Retrograde transneuronal transport of rabies virus through cerebello-thalamocortical circuits of primates. Soc Neurosci Abstr 23:1828.

Kemp JM, Powell TPS (1971) The connexions of the striatum and globus pallidus: synthesis and speculation. Philos Trans R Soc Lond B Biol Sci 262:441-457.

Kim R, Nakano K, Jayaraman A, Carpenter MB (1976) Projections of the globus pallidus and adjacent structures: an autoradiographic study in the monkey. J Comp Neurol 169:263-290.

Kuo J, Carpenter MB (1973) Organization of pallidothalamic projections in the rhesus monkey. J Comp Neurol 151:201-236.

Lynch JC, Hoover JE, Strick PL (1994) Input to the primate frontal eye field from the substantia nigra, superior colliculus, and dentate nucleus demonstrated by transneuronal transport. Exp Brain Res 100:181-186.

Mason CR, Miller LE, Houk JC (1998) Organization of reaching and grasping movements in the primate cerebellar nuclei as revealed by focal muscimol inactivations. J Neurophysiol 79:537-554.

Matelli M, Luppino G, Fogassi L, Rizzolatti G (1989) Thalamic input to inferior area 6 and area 4 in the macaque monkey. J Comp Neurol 280:468-488.

McLean JH, Shipley MT, Bernstein DI (1989) Golgi-like, transneuronal retrograde labeling with CNS injections of herpes simplex virus type 1 . Brain Res Bull 22:867-881.

Mesulam MM (1982) Tracing neural connections. New York: Wiley.

Middleton FA, Strick PL (1994) Anatomical evidence for cerebellar and basal ganglia involvement in higher cognitive function. Science 266:458-461.

Middleton FA, Strick PL (1996) The temporal lobe is a target of output from the basal ganglia. Proc Natl Acad Sci USA 93:8683-8687.

Middleton FA, Strick PL (1997) Dentate output channels: motor and cognitive components. Prog Brain Res 114:553-566.

Middleton FA, Strick PL (1998) Basal ganglia and cerebellar 'inputs' to dorsal and lateral prefrontal cortex. Soc Neurosci Abstr 24:644.

Mink JW, Thach WT (1991) Basal ganglia motor control: I. Nonexclusive relation of pallidal discharge to five movement modes. J Neurophysiol 65:273-300.

Nambu A, Yoshida S, Jinnai K (1988) Projection on the motor cortex of thalamic neurons with pallidal input in the monkey. Exp Brain Res 71:658-662.

Nambu A, Yoshida S, Jinnai K (1990) Discharge patterns of pallidal neurons with input from various cortical areas during movement in the monkey. Brain Res 519:183-191.

Nambu A, Yoshida S, Jinnai K (1991) Movement-related activity of thalamic neurons with input from the globus pallidus and projection to the motor cortex in the monkey. Exp Brain Res 84:279-284.

O'Donnell P, Lavin A, Enquist LW, Grace AA, Card JP (1997) Interconnected parallel circuits between rat nucleus accumbens and thalamus revealed by retrograde transynaptic transport of pseudorabies virus. J Neurosci 17:2143-2167.

Percheron G (1977) The thalamic territory of cerebellar afferents and the lateral region of the thalamus of the macaque in stereotaxic ventricular coordinates. J Hirnforsch 18:375-400.

Percheron G, Francois C, Talbi B, Yelnik J, Fenelon G (1996) The primate motor thalamus. Brain Res Rev 22:93-181.

Rinaman L, Card JP, Enquist LW (1993) Spatiotemporal responses of astrocytes, ramified microglia, and brain macrophages to central neuronal infection with pseudorabies virus. J Neurosci 13:685-702.
Rispal-Padel L, Cicirata F, Pons C (1982) Cerebellar nuclear topography of simple and synergistic movements in the alert baboon (Papio papio). Exp Brain Res 47:365-380.

Rosen GD, Harry JD (1990) Brain volume estimation from serial section measurements: a comparison of methodologies. J Neurosci Methods 35:115-124.

Rosene DL, Mesulam MM (1978) Fixation variables in horseradish peroxidase neurohistochemistry. I. The effects of fixation time and perfusion procedures upon enzyme activity. J Histochem Cytochem 26:28-39.

Rosene DL, Roy NJ, Davis BJ (1986) A cryoprotection method that facilitates cutting frozen sections of whole monkey brains for histological and histochemical processing without freezing artifact. J Histochem Cytochem 34:1301-1315.

Rouiller EM, Liang F, Babalian A, Moret V, Wiesendanger M (1994) Cerebellothalamocortical and pallidothalamocortical projections to the primary and supplementary motor cortical areas: a multiple tracing study in macaque monkeys. J Comp Neurol 345:185-213.

Sakai ST, Inase SM, Tanji J (1996) Comparison of cerebellothalamic and pallidothalamic projections in the monkey (Macaca fuscata): a double anterograde labeling study. J Comp Neurol 368:215-228.

Schell GR, Strick PL (1984) The origin of thalamic inputs to the arcuate premotor and supplementary premotor areas. J Neurosci 4:539-560.

Shindo K, Shima K, Tanji J (1995) Spatial distribution of thalamic projections to the supplementary motor area and the primary motor cortex: a retrograde labeling study in the macaque monkey. J Comp Neurol 357:98-116.

Sidibe M, Bevan MD, Bolam JP, Smith Y (1997) Efferent connections of the internal globus pallidus in the squirrel monkey: I. Topography and synaptic organization of the pallidothalamic projection. J Comp Neurol 382:323-347.

Stanton G (1980) Topographical organization of ascending cerebellar projections from the dentate and interposed nuclei in Macaca mulatta: an anterograde degeneration study. J Comp Neurol 190:699-731.

Stepniewska I, Preuss TM, Kaas JH (1994) Thalamic connections of the primary motor cortex (M1) of owl monkeys. J Comp Neurol 349:558-582.

Strick PL, Card JP (1992) Transneuronal mapping of neural circuits with alpha herpesviruses. In: Experimental neuroanatomy: a practical approach (Bolam JP, ed), pp 81-101. Oxford: Oxford UP.

Strick PL, Hoover JE, Mushiake H (1993) Evidence for "output channels" in the cerebellum and basal ganglia. In: Role of the cerebellum and basal ganglia in voluntary movement (Mano N, Hamada I, DeLong MR, eds), pp 171-180.

Suzuki H, Azuma M (1976) A glass-insulated "Elgiloy" microelectrode for recording unit activity in chronic monkey experiments. Clin Neurophysiol 41:93-95.

Thach WT, Perry JG, Kane SA, Goodkin HP (1993) Cerebellar nuclei: rapid alternating movement, motor somatotopy, and a mechanism for the control of muscle synergy. Rev Neurol (Paris) 149:607-628.

Tolbert DL, Bantli H (1979) An HRP and autoradiographic study of cerebellar corticonuclear-nucleocortical reciprocity in the monkey. Exp Brain Res 36:563-571.

Tolbert DL, Bantli H, Bloedel JR (1977) The intracerebellar nucleocortical projection in a primate. Exp Brain Res 30:425-434.

Tolbert DL, Bantli H, Bloedel JR (1978) Organizational features of the cat and monkey cerebellar nucleocortical projection. J Comp Neurol 182:39-56.

Ugolini G (1995) Specificity of rabies virus as a transneuronal tracer of motor networks: transfer from hypoglossal motoneurons to connected second-order and higher order central nervous system cell groups. J Comp Neurol 356:457-480.

van Kan PL, Houk JC, Gibson AR (1993) Output organization of intermediate cerebellum of the monkey. J Neurophysiol 69:57-73.

Zemanick MC, Strick PL, Dix RD (1991) Direction of transneuronal transport of herpes simplex virus 1 in the primate motor system is strain dependent. Proc Natl Acad Sci USA 88:8048-8051. 